\title{
Intrinsic functional connectivity of the central extended amygdala
}

\author{
Rachael M. Tillman'1* | Melissa D. Stockbridge ${ }^{2}$ | Brendon M. Nacewicz ${ }^{5}$ | \\ Salvatore Torrisi ${ }^{6}$ | Andrew S. Fox ${ }^{7,8}$ | Jason F. Smith ${ }^{*}$ |
}

Alexander J. Shackman ${ }^{1,3,4}$

\author{
${ }^{1}$ Department of Psychology, University of Maryland, College Park, Maryland 20742 \\ ${ }^{2}$ Department of Hearing and Speech Sciences, University of Maryland, College Park, Maryland 20742 \\ ${ }^{3}$ Neuroscience and Cognitive Science Program, University of Maryland, College Park, Maryland 20742 \\ ${ }^{4}$ Maryland Neuroimaging Center, University of Maryland, College Park, Maryland 20742 \\ ${ }^{5}$ Department of Psychiatry, University of Wisconsin-Madison, 6001 Research Park Boulevard, Madison, Wisconsin 53719 \\ ${ }^{6}$ Section on the Neurobiology of Fear and Anxiety, National Institute of Mental Health, Bethesda, Maryland 20892 \\ ${ }^{7}$ Department of Psychology, University of California, Davis, California 95616 \\ ${ }^{8}$ California National Primate Research Center, University of California, Davis, California 95616
}

\section{Correspondence}

Alexander J. Shackman, Biology-Psychology Building, University of Maryland, College Park, MD 20742, USA.

Email: shackman@umd.edu

\section{Funding information}

University of California, Davis; University of Maryland, College Park; University of Wisconsin-Madison; National Institutes of Health, Grant/Award Numbers: DA040717, MH107444

\begin{abstract}
The central extended amygdala (EAc)-including the bed nucleus of the stria terminalis (BST) and central nucleus of the amygdala (Ce)-plays a critical role in triggering fear and anxiety and is implicated in the development of a range of debilitating neuropsychiatric disorders. Although it is widely believed that these disorders reflect the coordinated activity of distributed neural circuits, the functional architecture of the EAc network and the degree to which the BST and the Ce show distinct patterns of functional connectivity is unclear. Here, we used a novel combination of imaging approaches to trace the connectivity of the BST and the Ce in 130 healthy, racially diverse, community-dwelling adults. Multiband imaging, high-precision registration techniques, and spatially unsmoothed data maximized anatomical specificity. Using newly developed seed regions, wholebrain regression analyses revealed robust functional connectivity between the BST and Ce via the sublenticular extended amygdala, the ribbon of subcortical gray matter encompassing the ventral amygdalofugal pathway. Both regions displayed coupling with the ventromedial prefrontal cortex (vmPFC), midcingulate cortex (MCC), insula, and anterior hippocampus. The BST showed stronger connectivity with the thalamus, striatum, periaqueductal gray, and several prefrontal territories. The only regions showing stronger functional connectivity with the Ce were neighboring regions of the dorsal amygdala, amygdalohippocampal area, and anterior hippocampus. These observations provide a baseline against which to compare a range of special populations, inform our understanding of the role of the EAc in normal and pathological fear and anxiety, and showcase image registration techniques that are likely to be useful for researchers working with "deidentified" neuroimaging data.

KEYWORDS

affective neuroscience, amygdala, anxiety, bed nucleus of the stria terminalis (BST/BNST), central extended amygdala
\end{abstract}

*Rachael M. Tillman and Jason F. Smith contributed equally to this study. 


\section{1 | INTRODUCTION}

When extreme, fear and anxiety can become debilitating (Grupe \& Nitschke, 2013; Salomon et al., 2015). Anxiety disorders are common and challenging to treat, imposing a staggering burden on public health, and underscoring the need to develop a more complete understanding of the distributed neural circuits governing the expression of fear and anxiety in humans (Bystritsky, 2006; Craske et al., 2017; DiLuca \& Olesen, 2014; Global Burden of Disease Collaborators, 2016; Griebel \& Holmes, 2013).
Converging lines of anatomical, mechanistic, and physiological evidence make it clear that the central extended amygdala (EAc) is a key hub in this circuitry (Figure 1a,b) (Avery, Clauss, \& Blackford, 2016; Davis, Walker, Miles, \& Grillon, 2010; Fox \& Shackman, in press; Goode \& Maren, 2017; Gungor \& Paré, 2016; Shackman \& Fox, 2016; Tovote, Fadok, \& Luthi, 2015). The EAc encompasses a collection of subcortical regions with similar cellular compositions, neurochemistry, gene expression, and structural connectivity and it encompasses the bed nucleus of the stria terminalis (BST), the central nucleus of the amygdala (Ce), the sublenticular extended amygdala (SLEA), and portions of

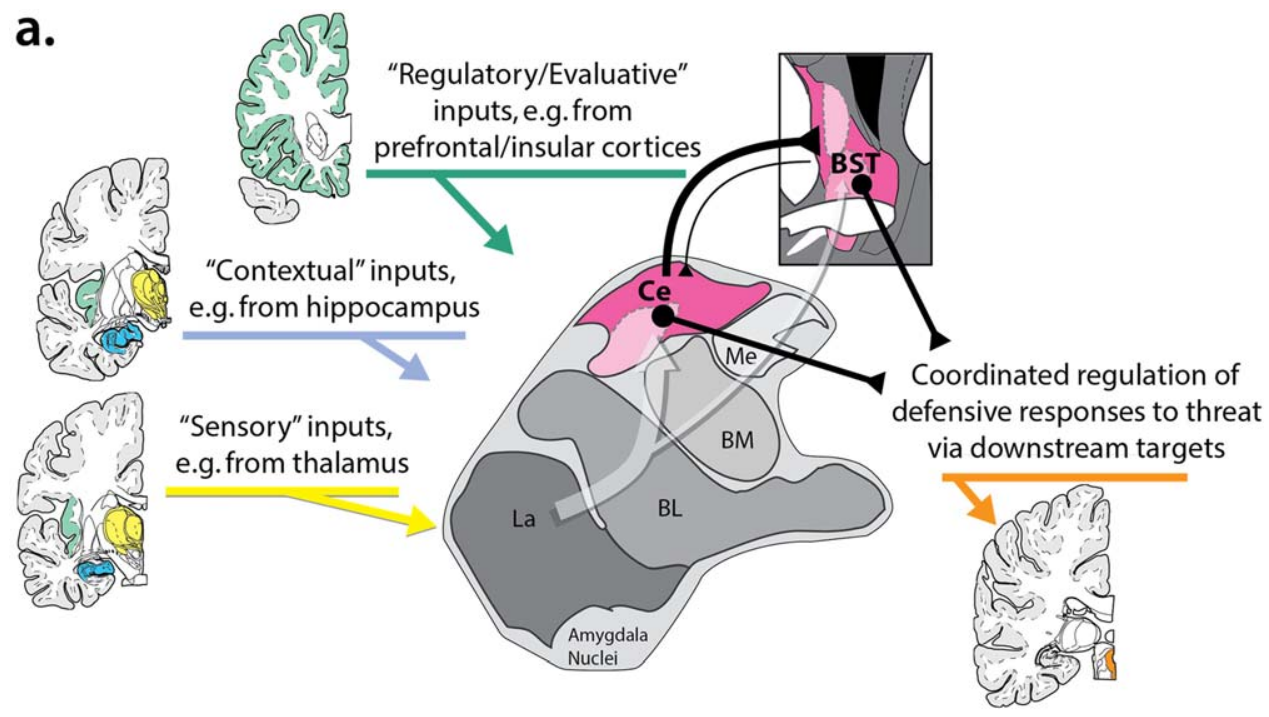

b.

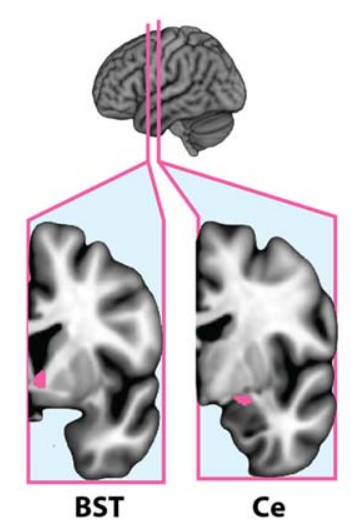

C.

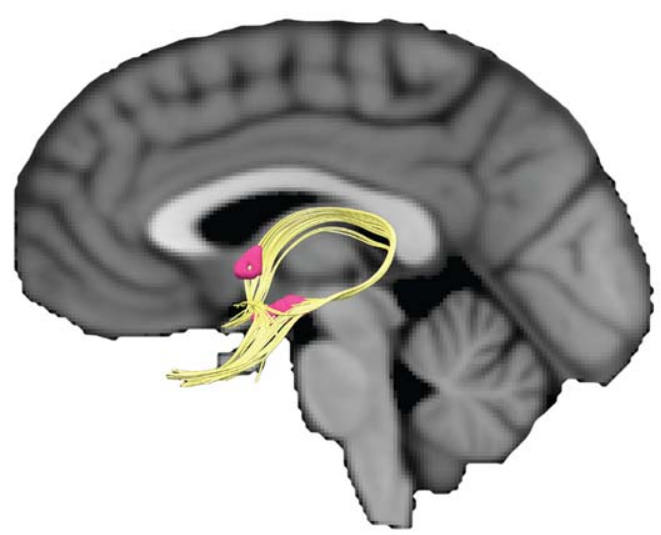

FIGURE 1 The EAc. (a) Simplified schematic of key EAc inputs and outputs in humans and other primates. The EAc (magenta) encompasses the BST, which encircles the anterior commissure, and the Ce. As shown by the translucent white arrow at the center of the figure, much of the sensory (yellow), contextual (blue), and regulatory (green) inputs to the EAc are indirect (i.e., polysynaptic), and first pass through adjacent amygdala nuclei before arriving at the Ce or the BST. Both regions are poised to orchestrate momentary states of fear and anxiety via dense projections to downstream effector regions (orange). Portions of this figure were adapted from the atlas of (Mai, Paxinos, \& Voss, 2007; see also Yilmazer-Hanke, 2012). (b) BST and Ce seeds. Figure depicts the location of the BST and Ce seeds used in the present study. See Supporting Information, Figure S5 for bilateral views and a more detailed description of seed derivation. (c) Structural connections of the EAc. In humans and other primates, the BST (dorsorostral magenta region) and the Ce (ventrocaudal magenta region) are structurally connected via two major fiber bundles (gold), the ventral amygdalofugal pathway and the stria terminalis (Johnston, 1923; Nauta, 1961; Yilmazer-Hanke, 2012). From the Ce, the ventral amygdalofugal pathway courses forward and medially, passing through the SLEA, a bridge of neurons harbored within the substantia innominata. The stria terminalis, which arches dorsally over the thalamus, provides a second, less direct connection between the two major divisions of the central extended amygdala. Figure depicts deterministic tractography (gold) of these two fiber bundles. Image kindly provided by Do Tromp. Abbreviations: $\mathrm{BL}=$ basolateral nucleus of the amygdala; $\mathrm{BM}=$ basomedial nucleus of the amygdala; BST = bed nucleus of the stria terminalis; $\mathrm{Ce}=$ central nucleus of the amygdala; $\mathrm{EAc}=$ central division of the extended amygdala; $\mathrm{La}=$ lateral nucleus of the amygdala; $\mathrm{Me}=$ medial nucleus of the amygdala; SLEA = sublenticular extended amygdala [Color figure can be viewed at wileyonlinelibrary.com] 
the accumbens shell (Alheid \& Heimer, 1988; Fox, Oler, Tromp, Fudge, \& Kalin, 2015a; Oler et al., 2017; Yilmazer-Hanke, 2012). It has long been recognized that the amygdala is connected to the BST via two major fiber bundles-the ventral amygdalofugal pathway (VA) and the stria terminalis (ST) (Avery et al., 2014; Kamali et al., 2015, 2016; Nauta, 1961) (Figure 1c)-and more recent tracing studies have identified a third, indirect pathway centered on the SLEA (Ce $\leftrightarrow$ SLEA $\leftrightarrow$ BSTL) (deCampo \& Fudge, 2013; Fudge et al., 2017; Oler et al., 2017). Anatomically, the $\mathrm{Ce}$ and the BST are both poised to trigger or orchestrate key signs of fear and anxiety-including alterations in arousal, behavioral inhibition, and neuroendocrine activity-via dense monoand polysynaptic projections to brainstem and subcortical effector regions (Fox et al., 2015a; Freese \& Amaral, 2009; Fudge et al., 2017).

Consistent with this neuroanatomy, mechanistic studies in rodents indicate that microcircuits within and between the BST and the Ce play a critical role in organizing defensive responses to a range of potentially threat-relevant cues and contexts (Calhoon \& Tye, 2015; Davis et al., 2010; Fox \& Shackman, in press; Goode \& Maren, 2017; Gungor \& Paré, 2016; Lange et al., 2017; Tovote et al., 2015) (Figure 1c). Although the BST and the Ce are often viewed as passive output relays for amygdala-mediated emotional learning (e.g., La $\rightarrow$ Ce/BST $\rightarrow$ effector regions; LeDoux, 2000, 2007; Pare \& Duvarci, 2012), more recent work in rodents has expanded this role to include relaying information about pain and aversive reinforcers (Yu et al., 2017), guiding attention to motivationally salient stimuli (Davis \& Whalen, 2001; Roesch, Esber, Li, Daw, \& Schoenbaum, 2012; Shackman et al., 2016a), learning aversive associations (Ciocchi et al., 2010; Han, Soleiman, Soden, Zweifel, \& Palmiter, 2015; Li et al., 2013; Penzo, Robert, \& Li, 2014; Penzo et al., 2015; Sato et al., 2015; Yu et al., 2017), and actively gating and regulating defensive responses (Ehrlich et al., 2009; Fadok et al., 2017; Gungor \& Paré, 2016; Pare \& Duvarci, 2012).

Although the causal contribution of the BST has yet to be explored in primates, the Ce has been shown to control defensive responses to potential threat in monkeys (Kalin, 2017; Kalin et al., 2016; Kalin, Shelton, \& Davidson, 2004). Similarly, rodents, monkeys, and humans with amygdala damage exhibit a profound lack of fear and anxiety in response to a broad spectrum of learned and innate dangers (Antoniadis, Winslow, Davis, \& Amaral, 2007; Bechara et al., 1995; Choi \& Kim, 2010; Davis \& Whalen, 2001; Feinstein, Adolphs, Damasio, \& Tranel, 2011; Feinstein, Adolphs, \& Tranel, 2016; Izquierdo, Suda, \& Murray, 2005; Kalin et al., 2004; Korn et al., 2017; Mason, Capitanio, Machado, Mendoza, \& Amaral, 2006; Oler, Fox, Shackman, \& Kalin, 2016).

Neuroimaging research indicates that heightened activity in the EAc is associated with elevated signs of fear and anxiety in both monkeys and humans (Alvarez et al., 2015; Banihashemi, Sheu, Midei, \& Gianaros, 2015; Cheng, Knight, Smith, \& Helmstetter, 2006; Cheng, Richards, \& Helmstetter, 2007; Fox et al., 2015b; Fox, Shelton, Oakes, Davidson, \& Kalin, 2008; Kalin, Shelton, Fox, Oakes, \& Davidson, 2005; Knight, Nguyen, \& Bandettini, 2005; Kragel \& LaBar, 2015; LaBar, Gatenby, Gore, LeDoux, \& Phelps, 1998; Shackman et al., 2013; Somerville et al., 2013; van Well, Visser, Scholte, \& Kindt, 2012; Wood, Ver Hoef, \& Knight, 2014). Among humans, the amygdala responds to a variety of threat-related cues (Costafreda, Brammer, David, \& Fu,
2008; Fusar-Poli et al., 2009; Lindquist, Satpute, Wager, Weber, \& Barrett, 2016; Sabatinelli et al., 2011; Sergerie, Chochol, \& Armony, 2008) and work using high-resolution $\mathrm{fMRI}$ indicates that the dorsal amygdala in the region of the $\mathrm{Ce}$ is particularly sensitive to aversive visual stimuli (Hrybouski et al., 2016).

Although less intensively studied than the $\mathrm{Ce}$, the BST is sensitive to emotional faces (Sladky et al., 2017), aversive images (Brinkmann et al., 2018), and a variety of threat-related cues (Alvarez, Chen, Bodurka, Kaplan, \& Grillon, 2011; Brinkmann et al., 2017b; Choi, Padmala, \& Pessoa, 2012; Grupe, Oathes, \& Nitschke, 2013; Herrmann et al., 2016; Klumpers et al., 2015; McMenamin, Langeslag, Sirbu, Padmala, \& Pessoa, 2014; Mobbs et al., 2010; Pedersen et al., 2017; Somerville, Whalen, \& Kelley, 2010; Somerville et al., 2013). While imaging research hints at potential functional differences between the two regions (Alvarez et al., 2011; Fox et al., 2015b; Meyer, Padmala, \& Pessoa, 2017; Shackman et al., 2017; Somerville et al., 2013), methodological limitations preclude decisive inferences (Fox \& Shackman, in press; Shackman \& Fox, 2016). Importantly, other work suggests that alterations in EAc function likely plays a key role in the development, maintenance, and recurrence of anxiety disorders, depression, and substance abuse (Avery et al., 2016; Brinkmann et al., 2017a, 2017b, 2018; Buff et al., 2017; Fox \& Kalin, 2014; Kaczkurkin et al., 2016; Münsterkötter et al., 2015; Shackman et al., 2016a, 2016b; Stevens et al., 2017; Williams et al., 2015; Wise \& Koob, 2014).

Although this vast literature leaves little doubt that the EAc plays a crucial role in evaluating and responding to a variety of potential threats, it does not act in isolation. Fear and anxiety reflect functional circuits that extend well beyond the borders of the EAc (Chang, Gianaros, Manuck, Krishnan, \& Wager, 2015; Fox \& Shackman, in press; Kragel, Knodt, Hariri, \& LaBar, 2016; Nummenmaa \& Saarimaki, in press; Pessoa, 2017; Shackman \& Fox, 2018; Shackman, Fox, \& Seminowicz, 2015; Wager et al., 2015). Anatomically, the BST and the Ce are embedded within a complex web of mono- and polysynaptically connected brain regions (Figure 1a) (Carrive \& Morgan, 2012; Fox et al., 2015a; Freese \& Amaral, 2009; Fudge et al., 2017; Oler et al., 2017; Ongur \& Price, 2000). This structural backbone includes subcortical regions, such as the periaqueductal gray (PAG), that are responsible for triggering specific signs of fear and anxiety (Amano et al., 1982; Assareh, Sarrami, Carrive, \& McNally, 2016; Bandler, Price, \& Keay, 2000; Chen et al., 2015; Fadok et al., 2017; Faull \& Pattinson, 2017; Motta, Carobrez, \& Canteras, 2017; Nashold, Wilson, \& Slaughter, 1969; Richardson \& Akil, 1977; Satpute et al., 2013; Tovote et al., 2016). It also encompasses a number of cortical regions implicated in the expression and regulation of fear and anxiety, including the anterior insula, dorsolateral prefrontal cortex, mid-cingulate cortex (MCC), and OFC (Birn et al., 2014; Buhle et al., 2014; Cavanagh \& Shackman, 2015; de la Vega, Chang, Banich, Wager, \& Yarkoni, 2016; Fox et al., 2010, 2015b; Grupe \& Nitschke, 2013; Mobbs et al., 2007, 2009, 2010; Shackman, McMenamin, Maxwell, Greischar, \& Davidson, 2009; Shackman et al., 2011; Stout, Shackman, Pedersen, Miskovich, \& Larson, 2017; Uddin, Kinnison, Pessoa, \& Anderson, 2014). While it is widely believed that the synchronized flow of information across this network underlies the human capacity for flexibly regulating fear and 
anxiety, the functional architecture of the EAc network and the degree to which the BST and the Ce are characterized by distinct patterns of functional connectivity remains incompletely understood.

Building on prior work (Table 1), we used a combination of imaging approaches to trace and compare the intrinsic functional connectivity of the BST and the Ce. Whole-brain "resting-state" functional MRI (fMRI) data were acquired from a relatively large $(n=130)$ sample of psychiatrically healthy, racially diverse, community-dwelling adults, providing increased statistical power and generalizability. Given the challenges of imaging the EAc (Fox et al., 2015a; Shackman \& Fox, 2016; Fox \& Shackman, in press), several techniques were used to maximize effective spatial resolution, including a multiband imaging sequence with $2-\mathrm{mm}^{3}$ nominal resolution, boundary-based co-registration (Greve \& Fischl, 2009), a novel brain-extraction ("skull-stripping") approach, and diffeomorphic normalization (Avants, Epstein, Grossman, \& Gee, 2008; Avants et al., 2010, 2011; Klein et al., 2009). To further enhance anatomical specificity, analyses were conducted using spatially unsmoothed data and newly developed extended amygdala seeds. Collectively, these techniques enabled us to compare the intrinsic functional connectivity of the BST and the Ce with enhanced statistical sensitivity and anatomical precision (Table 1). Understanding these functional networks is important: it would provide a baseline against which to compare a range of special populations-including individuals at risk for developing mental illness and patients suffering from psychiatric disorders-and it would inform our understanding of the EAc's role in normal and pathological fear and anxiety.

\section{2 | MATERIALS AND METHODS}

\section{1 | Subjects}

Data were extracted from the publicly available Nathan Kline InstituteRockland Sample (NKI-RS) (http://fcon_1000.projects.nitrc.org/indi/ enhanced; Nooner et al., 2012) for 185 adults (18-40 years old). Exclusionary criteria included: positive drug urine screen $(n=12)$; selfreported lifetime bipolar disorder, neurological disorder, pervasive developmental disorder, or psychosis/schizophrenia ( $n=14)$; incomplete MRI data $(n=15)$; and incomplete demographic data $(n=5)$. Using procedures detailed below, 18 additional subjects were excluded due to excessive motion artifact $(n=8)$, susceptibility artifact $(n=9)$, or unusable T1 scans $(n=1)$. The final sample consisted of 130 subjects (59 males, $M=25.3$ years, $S D=6.1$ ). Additional demographic details can be found in the Supporting Information.

\section{2 | Data acquisition}

MRI data were acquired using a Siemens Magnetom Trio Tim 3 T scanner and 32-channel head-coil (http://fcon_1000.projects.nitrc.org/indi/ enhanced/mri_protocol.html). T1-weighted anatomical images were acquired using a magnetization-prepared, rapid-acquisition, gradientecho sequence (inversion time: $900 \mathrm{~ms}$; repetition time: 1,900 ms; echo time: $2.52 \mathrm{~ms}$; flip angle: $9^{\circ}$; field-of-view: $250 \times 250$; matrix: $256 \times$ 256; number of slices: 176 sagittal; slice thickness: $1 \mathrm{~mm}$ ). Building on prior work with partial-brain coverage (Gorka, Torrisi, Shackman, Grillon, \& Ernst, 2017; Torrisi et al., 2015), functional scans were obtained using a $\mathrm{T}_{2}{ }^{*}$-weighted echo-planar image (EPI) sequence (multiband acceleration: 4; repetition time: $1,400 \mathrm{~ms}$; echo time: $30 \mathrm{~ms}$; flip angle: $65^{\circ}$; number of excitations: 1; field-of-view: $224 \times 224 \mathrm{~mm}$; number of slices: 64 oblique-axial; matrix: $112 \times 112$; slice thickness: $2 \mathrm{~mm}$; gap: $\sim 0 \mathrm{~mm}$; volumes: 404), enabling us to survey the entire brain.

\section{3 | Data processing pipeline}

\subsection{1 | Brain extraction and normalization}

Given our focus on the BST and the Ce, methods were optimized to minimize spatial normalization error and incidental spatial blurring. Consistent with other work (Acosta-Cabronero, Williams, Pereira, Pengas, \& Nestor, 2008; Fein et al., 2006; Fischmeister et al., 2013), unpublished observations by our group demonstrate that the quality of spatial normalization is enhanced by using a brain-extracted (i.e., "skullstripped" or "de-skulled") template and brain-extracted T1 images. This advantage is particularly evident for publicly available datasets, such as the NKI-RS, where portions of the skull and tissue in the region of the face have been manually removed ("de-faced") by the curators to mitigate risks to subject confidentiality (i.e., "anonymized" or "de-identified"). However, this benefit is only realized when the quality of the extraction is sufficiently high and consistent, as with images that have been manually extracted by an experienced neuroanatomist. To ensure consistently high-quality extractions, we implemented a multi-tool strategy (for a similar approach, see Meyer et al., 2017; Najafi, Kinnison, \& Pessoa, 2017). For each inhomogeneity-corrected (using N4; Tustison et al., 2014) T1 image, six extraction masks were generated. Five masks were generated using BET (Smith, 2002), BSE (Shattuck, Sandor-Leahy, Schaper, Rottenberg, \& Leahy, 2001), 3dSkullstrip (Cox, 1996), ROBEX (Iglesias, Liu, Thompson, \& Tu, 2011), and SPM unified segmentation (Ashburner \& Friston, 2005), respectively. The sixth mask was generated by applying the inverse spatial transformation (see below) to the MNI152 brain mask distributed with FSL. Specifically, for each subject: (a) the defaced T1 image was spatially normalized to the MNI152 template using the unified segmentation approach implemented in SPM12; (b) the 1-mm MNI152 template was defaced to match the idiosyncratic defacing of the T1 image; (c) the original T1 image was normalized to the individually defaced 1-mm template using SyN; and (d) the inverse transformation was used to "reverse-normalize" the MNI152 brain mask distributed with FSL to native space. Next, a best-estimate extraction mask was determined by consensus, requiring agreement across four or more extraction techniques. Using this mask, each T1 image was extracted and spatially normalized to the 1-mm MNI152 template using the high-precision diffeomorphic approach implemented in SyN (mutual information cost function; Avants et al., 2008, 2010, 2011; Klein et al., 2009). The average of the 130 normalized T1 images is depicted in Supporting Information, Figure S1.

\subsection{2 | EPI data}

The first 3 volumes of each EPI scan were removed and the remaining volumes were de-spiked and slice-time corrected using default settings 







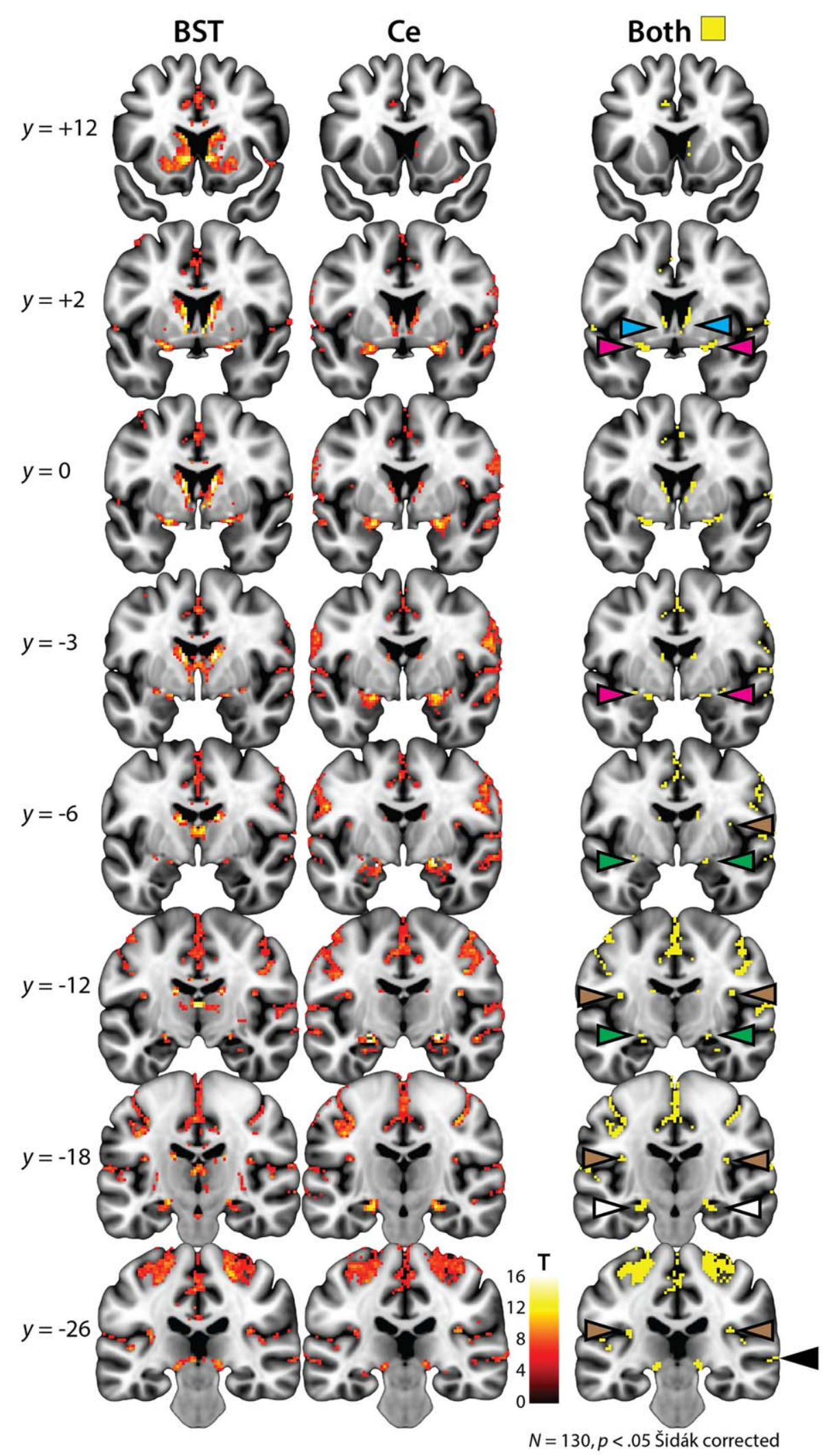

FIGURE 2 Intrinsic functional connectivity of the EAc. Left and center columns depict the results of whole-brain regression analyses for the BST and the Ce seed regions, respectively, conservatively thresholded at $p<.05$ whole-brain Šidák corrected. The right column depicts the intersection or conjunction (Boolean "AND") of the two thresholded maps (Nichols et al., 2005). The BST seed showed significant functional connectivity with neighboring voxels in the basal forebrain (cyan arrowheads) and voxels in the region of the Ce (green arrowheads), while the Ce seed showed significant coupling with neighboring voxels in the dorsal amygdala and distal voxels in the region of the BST. Analyses also demonstrated that the BST and Ce exhibit robust functional connectivity with intermediate voxels located along the path of the ventral amygdalofugal pathway in the sublenticular extended amygdala (magenta arrowheads). Finally, both regions showed significant coupling with the amygdalohippocampal area and anterior hippocampus (white arrowheads), posterior insula (brown arrowheads), and superior temporal sulcus (black arrowheads). Note: Results are depicted here and reported in the accompanying tables for clusters of at least $80 \mathrm{~mm}^{3}$. See Figures 3 and 5 for additional views of these contrasts. Abbreviations: BST = bed nucleus of the stria terminalis; Ce $=$ central nucleus of the amygdala; $E A c=$ central division of the extended amygdala; $L=$ left hemisphere; $R=$ right hemisphere [Color figure can be viewed at wileyonlinelibrary.com] 
TABLE 2 Regions showing significant functional connectivity with the BST ${ }^{\mathrm{a}}$

\begin{tabular}{llllll}
$\boldsymbol{x}$ & $\boldsymbol{y}$ & $\boldsymbol{z}$ & $\boldsymbol{t}$ & $\mathrm{mm}^{\mathbf{3}}$ & Hemisphere \\
\hline 11 & 45 & 1 & 7.65 & 176 & $\mathrm{~B}$ \\
-21 & 41 & 29 & 8.55 & 352 & $\mathrm{~L}$ \\
-25 & 33 & 49 & 10.03 & 896 & $\mathrm{~L}$ \\
\hline 27 & 32 & 35 & 8.75 & 888 & $\mathrm{~B}$ \\
-42 & 23 & -5 & 7.86 & 272 & $\mathrm{~L}$ \\
-5 & 3 & 0 & 21.04 & 49,072 & $\mathrm{~B}$ \\
-6 & 4 & -1 & 21.04 & 9,128 & $\mathrm{~B}$
\end{tabular}

\section{Region(s)/subregions}

Cingulate sulcus, pregenual

Superior frontal sulcus, anterior

Superior frontal sulcus, anterior

Superior frontal sulcus, anterior

Orbitofrontal cortex, basal operculum

Midline $^{b}$

Basal forebrain: caudate, putamen, globus pallidus, nucleus accumbens, rostrodorsal hypothalamus, piriform cortex, sublenticular extended amygdala (ventral amygdalofugal pathway), dorsal amygdala (central and medial nuclei), amygdalohippocampal area and anterior hippocampus, thalamus, brainstem

\begin{tabular}{llllll}
\hline-6 & -43 & 5 & 12.96 & 7,648 & B \\
\hline 1 & 19 & 37 & 11.7 & 3,072 & L
\end{tabular}

Posterior cingulate/Precuneus

Cingulate: cingulate sulcus, midcingulate; cingulate sulcus, posterior; juxtapositional lobule

\begin{tabular}{|llllll}
\hline 11 & 18 & 33 & 10.27 & 480 & $\mathrm{R}$ \\
\hline 1 & 53 & -5 & 9.67 & 328 & $\mathrm{~B}$
\end{tabular}

Cingulate: Cingulate sulcus, pregenual; Cingulate sulcus, midcingulate

Ventromedial prefrontal cortex: OP10 $/ \mathrm{m}^{\mathrm{c}}$; inferior frontopolar gyrus; rostral gyrus; anterior cingulate cortex, pregenual

\begin{tabular}{|c|c|c|c|c|c|c|}
\hline-3 & -25 & -3 & 9.48 & 80 & $\mathrm{~L}$ & Periaqueductal gray, dorsolateral \\
\hline-53 & 2 & -1 & 7.97 & 136 & $\mathrm{~L}$ & Superior temporal gyrus, planum polare \\
\hline-39 & 1 & 59 & 7.12 & 136 & $\mathrm{~L}$ & Precentral sulcus \\
\hline 1 & -13 & -23 & 8.81 & 88 & $\mathrm{R}$ & Cerebellum \\
\hline-37 & -15 & 17 & 10.79 & 1,648 & $\mathrm{~L}$ & $\begin{array}{l}\text { Posterior insula: central operculum, parietal } \\
\text { operculum, posterior insula (dorsal portion } \\
\text { of the long gyri), Heschl's gyrus }\end{array}$ \\
\hline 53 & -16 & 5 & 9.57 & 2,224 & $\mathrm{R}$ & $\begin{array}{l}\text { Posterior insula: central operculum, parietal } \\
\text { operculum, posterior insula (dorsal portion } \\
\text { of the long gyri), Heschl's gyrus }\end{array}$ \\
\hline 31 & -17 & 3 & 7.43 & 184 & $\mathrm{R}$ & Putamen \\
\hline 13 & -17 & 39 & 8.01 & 160 & $\mathrm{~B}$ & Cingulate sulcus, posterior \\
\hline-27 & -19 & 5 & 7.91 & 112 & $\mathrm{~L}$ & Putamen \\
\hline 7 & -21 & -1 & 10.85 & 152 & $\mathrm{R}$ & Thalamus \\
\hline 69 & -22 & -3 & 8.19 & 544 & $\mathrm{R}$ & Superior temporal sulcus \\
\hline-20 & -29 & 57 & 11.7 & 3,144 & $\mathrm{~L}$ & Central sulcus \\
\hline 21 & -29 & 57 & 13.12 & 3,024 & $\mathrm{R}$ & Central sulcus \\
\hline 26 & -37 & 57 & 8.98 & 360 & $\mathrm{~B}$ & Postcentral sulcus \\
\hline-19 & -37 & 65 & 8.04 & 272 & $\mathrm{~L}$ & Postcentral gyrus \\
\hline 57 & -57 & 21 & 7.53 & 176 & $\mathrm{R}$ & Angular gyrus \\
\hline 54 & -62 & 31 & 7.04 & 176 & $\mathrm{R}$ & Lateral occipital cortex \\
\hline-9 & -69 & 5 & 8.29 & 256 & $\mathrm{~L}$ & Calcarine sulcus \\
\hline 31 & -72 & -37 & 8.41 & 344 & $\mathrm{~B}$ & Cerebellum \\
\hline-31 & -80 & -37 & 8.17 & 504 & $\mathrm{~L}$ & Cerebellum \\
\hline
\end{tabular}

(Continues) 
TABLE 2 (Continued)

\begin{tabular}{lllllll}
$\boldsymbol{x}$ & $\boldsymbol{y}$ & $\mathbf{z}$ & $\boldsymbol{t}$ & $\mathrm{mm}^{\mathbf{3}}$ & Hemisphere & Region(s)/subregions \\
-7 & -81 & 1 & 7.94 & 384 & $\mathrm{~L}$ & Calcarine sulcus \\
-35 & -83 & -19 & 7.03 & 96 & $\mathrm{~L}$ & Lateral occipital cortex/fusiform, occipital \\
25 & -85 & -19 & 8.08 & 328 & $\mathrm{R}$ & Fusiform, occipital \\
15 & -93 & 1 & 7.9 & 80 & $\mathrm{R}$ & Occipital pole \\
\hline
\end{tabular}

Note. Abbreviations: B, bilateral; $\mathrm{Ce}$, central nucleus of the amydala; $\mathrm{L}$, left hemisphere; $\mathrm{R}$, right hemisphere.

${ }^{a}$ Whole-brain regression analysis $\left(p<.05\right.$, whole-brain Šidák corrected, $k \geq 80 \mathrm{~mm}^{3}$ ).

${ }^{\mathrm{b}}$ For large clusters, subregions were identified using $T \geq 7$ and are shown in italics.

${ }^{\mathrm{c}}$ Areas 10r/m and 11 as described by Ongur, Ferry, and Price (2003).

in AFNI (Cox, 1996). Recent methodological work indicates that despiking is more effective than "scrubbing" (Jo et al., 2013; Power, Schlaggar, \& Petersen, 2015; Siegel et al., 2014) for attenuating motion-related artifacts in intrinsic functional connectivity. Spike- and slice-time-corrected EPI data were co-registered to the corresponding brain-extracted, native-space T1 image using the boundary-based registration technique implemented in FSL (Greve \& Fischl, 2009) and converted to a compatible file format using Convert3d (https:// sourceforge.net/p/c3d). Motion correction was then performed using ANTS (https://stnava.github.io/ANTs). The maximum value of the frame-to-frame displacement was calculated for each subject and $z$ transformed. Subjects with a $z$-score $>1.96(p=.05)$ were excluded $(n=8)$. Residual displacement in final dataset was negligible (median $=0.11 \mathrm{~mm}, S D=0.07 \mathrm{~mm}$, maximum $=0.43 \mathrm{~mm}$ ). To minimize incidental spatial blurring, the transformation matrices for motion correction, co-registration, and spatial normalization were concatenated and applied to the EPI data in a single step. Normalized EPI data were resampled to $2-\mathrm{mm}^{3}$ voxels using fifth-order splines. To maximize spatial resolution, no additional spatial filters were applied, consistent with recent recommendations (Stelzer, Lohmann, Mueller, Buschmann, \& Turner, 2014; Turner \& Geyer, 2014). Each EPI and T1 dataset was visually inspected before and after processing for quality assurance. To quantify susceptibility artifact in the medial temporal lobe (MTL), we computed the ratio of mean signal in the amygdala relative to the caudate and putamen separately for each hemisphere and subject and then standardized across subjects (i.e., $z$-transformed). Preliminary visual inspection indicated that values $>\sim 2.50$ were associated with substantial signal loss ("drop-out") in the MTL. Accordingly, subjects with zscores $<-2.50$ were excluded $(n=9)$ (for a similar approach, see Birn et al., 2014). To attenuate physiological noise, white matter (WM) and cerebrospinal fluid (CSF) time-series were identified by thresholding the tissue prior images distributed with FSL, as in prior work by our group (Birn et al., 2014) and others (Coulombe, Erpelding, Kucyi, \& Davis, 2016). The EPI time-series was orthogonalized with respect to the first 3 right eigenvectors of the data covariance matrix from the WM and CSF compartments (Behzadi, Restom, Liau, \& Liu, 2007), a Legendre polynomial series (first- to fifth-order), and motion estimates (6 parameters lagged by 0,1 , and 2 volumes), consistent with recent recommendations (Hallquist, Hwang, \& Luna, 2013). Orthogonalized time-series were bandpass filtered $(0.009-0.10 \mathrm{~Hz})$ using AFNI and rescaled to zero-mean unit variance in MATLAB. Using $3 \mathrm{dFWHMx}$, the mean spatial smoothness of the orthogonalized data was estimated to be $\sim 2.28 \mathrm{~mm}^{3}$.

\subsection{3 | Seed regions}

The BST seed was implemented using a previously published probabilistic region of interest thresholded at 25\% (Theiss, Ridgewell, McHugo, Heckers, \& Blackford, 2017). Building on prior work by our group (Birn et al., 2014; Nacewicz, Alexander, Kalin, \& Davidson, 2014; Najafi et al., 2017; Oler et al., 2012, 2017), the Ce was manually prescribed by an experienced neuroanatomist (B.M.N.) using a specially processed version of the CITI168 high-resolution $(0.7 \mathrm{~mm})$, multimodal (T1/T2) probabilistic template (http://evendim.caltech.edu/amygdala-atlas; Tyszka \& Pauli, 2016) and guided by the atlas of Mai et al. (2007). The methods used for processing the template and prescribing the Ce seed are detailed in the Supporting Information, Figures S2-S5. Consistent with prior reports (Birn et al., 2014; Entis, Doerga, Barrett, \& Dickerson, 2012; Hrybouski et al., 2016), visual inspection indicated that this approach provides enhanced anatomical sensitivity and selectivity compared to the more widely used centromedial amygdala region-ofinterest distributed with FSL (Amunts et al., 2005) (Supporting Information, Figure S5). The BST and Ce seeds are depicted in Figure $1 \mathrm{~b}$ and Supporting Information, Figure S6. To minimize partial volume artifacts, seeds were decimated to the 2-mm MNI template using an iterative procedure that maintained a consistent seed volume across templates. Specifically, each seed was minimally smoothed (2.24 mm FWHM Gaussian) and the voxel size was dilated by $0.1 \mathrm{~mm}$ and resliced (linear interpolation), enabling us to identify a threshold that approximated the original seed volume and better preserved anatomical boundaries (Left BST: $96 \mathrm{~mm}^{3}$; Right BST: $96 \mathrm{~mm}^{3}$; Left Ce: $152 \mathrm{~mm}^{3}$; Right Ce: $152 \mathrm{~mm}^{3}$ ).

\section{$2.4 \mid$ Analytic plan}

We adopted a standard a priori seed-based approach to quantifying intrinsic functional connectivity (Biswal, Yetkin, Haughton, \& Hyde, 1995; Fox et al., 2005). For each subject, SPM12 (http://www.fil.ion. ucl.ac.uk/spm/software/spm12) and in-house MATLAB code was used to perform a voxelwise regression between the artifact-attenuated, average seed time series and voxel times series throughout the brain. Single-subject regression analyses were performed using the Cochrane-Orcutt procedure for estimating autoregressive error, which is more efficient and potentially less biased than ordinary least-squares (Stocker, 2007). In order to identify regions showing consistent functional connectivity with the BST or Ce seeds across subjects, we tested 
TABLE 3 Regions showing significant functional connectivity with the $\mathrm{Ce}^{\mathrm{a}}$

\begin{tabular}{|c|c|c|c|c|c|c|}
\hline$x$ & $y$ & $z$ & $t$ & $\mathrm{~mm}^{3}$ & Hemisphere & Region(s)/subregions \\
\hline 1 & 59 & 19 & 8.29 & 504 & $\mathrm{~B}$ & Dorsomedial prefrontal cortex: BA10 \\
\hline 1 & 53 & -13 & 8.7 & 600 & B & $\begin{array}{l}\text { Ventromedial prefrontal cortex: OP } 10 \mathrm{r} / \mathrm{m}^{\mathrm{c}} \text {; inferior } \\
\text { frontopolar gyrus; rostral gyrus }\end{array}$ \\
\hline 8 & 39 & -15 & 7.27 & 112 & $\mathrm{R}$ & $\begin{array}{l}\text { Ventromedial prefrontal cortex: inferior } \\
\text { frontopolar gyrus, straight gyrus }\end{array}$ \\
\hline 34 & 37 & -13 & 7.15 & 96 & $\mathrm{R}$ & $\begin{array}{l}\text { Orbitofrontal cortex: OP } 11,{ }^{c} \text { anterior orbital } \\
\text { gyrus }\end{array}$ \\
\hline-19 & 37 & 43 & 7.92 & 392 & $\mathrm{~L}$ & Superior frontal sulcus, anterior \\
\hline 39 & 9 & -15 & 7.84 & 176 & $\mathrm{R}$ & Anterior insula: transverse insular gyrus \\
\hline 9 & 3 & 3 & 10.11 & 424 & $\mathrm{R}$ & $\begin{array}{l}\text { Basal forebrain: caudate, bed nucleus of the stria } \\
\text { terminalis, rostrodorsal hypothalamus }\end{array}$ \\
\hline-5 & 1 & 1 & 10.56 & 376 & $\mathrm{~L}$ & $\begin{array}{l}\text { Basal forebrain: caudate, bed nucleus of the stria } \\
\text { terminalis, rostrodorsal hypothalamus }\end{array}$ \\
\hline 57 & -5 & 23 & 12.64 & 12,736 & B & Central cortex ${ }^{\mathrm{b}}$ \\
\hline 57 & -5 & 23 & 12.64 & 3,024 & $\mathrm{R}$ & Central sulcus \\
\hline-3 & -22 & 45 & 10.87 & 1,096 & B & $\begin{array}{l}\text { Cingulate sulcus, posterior; Cingulate sulcus, midcingu- } \\
\text { late }\end{array}$ \\
\hline-1 & -31 & 57 & 8.44 & 160 & B & Precentral gyrus \\
\hline-52 & -7 & 25 & 11.53 & 6,912 & $\mathrm{~L}$ & Central sulcus \\
\hline 23 & -9 & -13 & 22.02 & 2,696 & $\mathrm{R}$ & $\begin{array}{l}\text { Basal forebrain: piriform cortex, sublenticular extended } \\
\text { amygdala (ventral amygdalofugal pathway), amygdala } \\
\text { (amygdalohippocampal area, basolateral, basomedial, } \\
\text { cortical, lateral, and medial), anterior hippocampus, } \\
\text { brainstem }\end{array}$ \\
\hline-19 & -11 & -13 & 20.91 & 2,720 & $\mathrm{~L}$ & $\begin{array}{l}\text { Basal forebrain: putamen, piriform cortex, sublenticular } \\
\text { extended amygdala (ventral amygdalofugal pathway), } \\
\text { amygdala (amygdalohippocampal area, basolateral, } \\
\text { basomedial, cortical, lateral, and medial), anterior } \\
\text { hippocampus, brainstem }\end{array}$ \\
\hline 51 & -12 & -13 & 10.6 & 4,904 & $\mathrm{R}$ & $\begin{array}{l}\text { Temporal lobe: superior temporal gyrus, } \\
\text { planum polare; parietal operculum; superior temporal } \\
\text { sulcus }\end{array}$ \\
\hline-37 & -15 & 17 & 10.73 & 6,400 & $\mathrm{~L}$ & $\begin{array}{l}\text { Posterior insula: central operculum, parietal operculum, } \\
\text { posterior insula (dorsal portion of the long gyri), } \\
\text { planum temporale, Heschl's gyrus, superior temporal } \\
\text { sulcus }\end{array}$ \\
\hline 39 & -15 & 17 & 10.89 & 1,096 & $\mathrm{R}$ & $\begin{array}{l}\text { Posterior insula: central operculum, parietal operculum, } \\
\text { posterior insula (dorsal portion of the long gyri) }\end{array}$ \\
\hline 53 & -23 & 45 & 6.38 & 80 & $\mathrm{R}$ & Postcentral sulcus \\
\hline 53 & -27 & 57 & 6.73 & 104 & $\mathrm{R}$ & Postcentral gyrus \\
\hline 25 & -37 & 59 & 8.3 & 592 & $\mathrm{R}$ & Postcentral sulcus \\
\hline-44 & -50 & -17 & 8.1 & 192 & $\mathrm{~L}$ & $\begin{array}{l}\text { Temporal lobe: inferior temporal gyrus, temporooccipi- } \\
\text { tal; fusiform, temporooccipital }\end{array}$ \\
\hline 37 & -52 & -21 & 7.99 & 208 & $\mathrm{R}$ & $\begin{array}{l}\text { Temporal lobe: inferior temporal gyrus, temporooccipi- } \\
\text { tal; fusiform, temporooccipital }\end{array}$ \\
\hline-1 & -53 & 17 & 13.43 & 7,632 & B & Posterior cingulate/precuneus \\
\hline 57 & -63 & 11 & 9.33 & 2,272 & $\mathrm{R}$ & Lateral occipital cortex \\
\hline 29 & -83 & -19 & 6.39 & 88 & $\mathrm{R}$ & Fusiform, occipital \\
\hline
\end{tabular}

Note. Abbreviations: B, bilateral; BA, Brodmann area; Ce, central nucleus of the amydala; L, left hemisphere; $\mathrm{R}$, right hemisphere.

${ }^{a}$ Whole-brain regression analysis $\left(p<.05\right.$, whole-brain Šidák corrected, $k \geq 80 \mathrm{~mm}^{3}$ ).

${ }^{\mathrm{b}}$ For large clusters, subregions were identified using $T \geq 7$ and are shown in italics.

${ }^{c}$ Areas $10 \mathrm{r} / \mathrm{m}$ and 11 as described by Ongur et al. (2003). 
TABLE 4 Regions showing significant functional connectivity with both the BST and the $\mathrm{Ce}^{\mathrm{a}}$

\begin{tabular}{|c|c|c|c|c|c|}
\hline$x$ & y & $z$ & $\mathrm{~mm}^{3}$ & Hemisphere & Region(s)/subregions \\
\hline 1 & 61 & 21 & 48 & $\mathrm{R}$ & Dorsomedial prefrontal cortex: BA10 \\
\hline 3 & 59 & 17 & 16 & $\mathrm{R}$ & Dorsomedial prefrontal cortex: BA10 \\
\hline 1 & 57 & 13 & 24 & $\mathrm{R}$ & Dorsomedial prefrontal cortex: BA10 \\
\hline 1 & 53 & 19 & 80 & $\mathrm{R}$ & Dorsomedial prefrontal cortex: BA10 \\
\hline-1 & 49 & 27 & 24 & $\mathrm{~L}$ & Dorsomedial prefrontal cortex: BA10 \\
\hline 1 & 39 & -15 & 296 & $\mathrm{R}$ & $\begin{array}{l}\text { Ventromedial prefrontal cortex: OP } 10 \mathrm{r} / \mathrm{m}^{\mathrm{b}} \text {; } \\
\text { inferior frontopolar gyrus; rostral gyrus }\end{array}$ \\
\hline-21 & 27 & 37 & 304 & $\mathrm{~L}$ & Superior frontal sulcus, anterior \\
\hline 55 & 7 & -3 & 8 & $\mathrm{R}$ & Temporal pole \\
\hline 63 & 7 & -1 & 664 & $\mathrm{R}$ & Planum temporale \\
\hline 9 & 5 & -1 & 384 & $\mathrm{R}$ & $\begin{array}{l}\text { Basal forebrain: caudate, bed nucleus of the } \\
\text { stria terminalis, rostrodorsal hypothalamus }\end{array}$ \\
\hline-9 & 5 & 35 & 3,448 & $\mathrm{~L}$ & $\begin{array}{l}\text { Cingulate: cingulate sulcus, posterior midcin- } \\
\text { gulate; cingulate sulcus, posterior }\end{array}$ \\
\hline-5 & 3 & -1 & 312 & $\mathrm{~L}$ & $\begin{array}{l}\text { Basal forebrain: caudate, bed nucleus of the } \\
\text { stria terminalis }\end{array}$ \\
\hline 5 & 1 & -3 & 8 & $\mathrm{R}$ & Bed nucleus of the stria terminalis \\
\hline-53 & 1 & -1 & 40 & $\mathrm{~L}$ & Planum polare \\
\hline 53 & 1 & -1 & 24 & $\mathrm{R}$ & Planum polare \\
\hline-1 & 1 & 47 & 8 & $\mathrm{~L}$ & Juxtapositional lobule \\
\hline-17 & -3 & -15 & 376 & $\mathrm{~L}$ & $\begin{array}{l}\text { Dorsal amygdala: amygdalohippocampal area, } \\
\text { central, cortical, medial }\end{array}$ \\
\hline 63 & -3 & 17 & 2,640 & $\mathrm{R}$ & Central sulcus \\
\hline 61 & -5 & -13 & 392 & $\mathrm{R}$ & Superior temporal sulcus \\
\hline 29 & -11 & -23 & 976 & $\mathrm{R}$ & Hippocampus \\
\hline-41 & -15 & 31 & 2,648 & $\mathrm{~L}$ & Central sulcus \\
\hline 5 & -15 & 73 & 8 & $\mathrm{R}$ & Precentral gyrus \\
\hline 63 & -17 & -7 & 8 & $\mathrm{R}$ & Superior temporal sulcus \\
\hline-53 & -17 & 9 & 8 & $\mathrm{~L}$ & Heschl's gyrus \\
\hline-21 & -19 & -17 & 616 & $\mathrm{~L}$ & $\begin{array}{l}\text { Hippocampus/dorsal amygdala: basolateral, } \\
\text { basomedial, central, medial }\end{array}$ \\
\hline-57 & -19 & 9 & 152 & $\mathrm{~L}$ & Planum temporale \\
\hline 13 & -19 & 39 & 40 & $\mathrm{R}$ & Cingulate sulcus, posterior \\
\hline 3 & -19 & 67 & 16 & $\mathrm{R}$ & Precentral gyrus \\
\hline-47 & -25 & 3 & 880 & $\mathrm{~L}$ & Planum temporale \\
\hline 47 & -25 & 7 & 728 & $\mathrm{R}$ & Planum temporale \\
\hline-25 & -31 & 67 & 96 & $\mathrm{~L}$ & Postcentral gyrus \\
\hline 3 & -33 & 49 & 16 & $\mathrm{R}$ & Posterior cingulate \\
\hline 27 & -37 & 55 & 232 & $\mathrm{R}$ & Postcentral sulcus \\
\hline-21 & -39 & 63 & 128 & $\mathrm{~L}$ & Postcentral gyrus \\
\hline 3 & -39 & 63 & 8 & $\mathrm{R}$ & Postcentral gyrus \\
\hline 11 & -53 & 1 & 6,792 & $\mathrm{R}$ & Posterior cingulate/precuneus \\
\hline 55 & -57 & 19 & 136 & $\mathrm{R}$ & Angular gyrus \\
\hline
\end{tabular}


TABLE 4 (Continued)

\begin{tabular}{llllll}
$\boldsymbol{x}$ & $\boldsymbol{y}$ & $\boldsymbol{z}$ & $\mathrm{mm}^{3}$ & Hemisphere & Region(s)/subregions \\
45 & -59 & 29 & 8 & $\mathrm{R}$ & Lateral occipital cortex \\
31 & -85 & -19 & 88 & $\mathrm{R}$ & Occipital fusiform \\
\hline
\end{tabular}

Note. Abbreviations: B, bilateral; BA, Brodmann area; BST, bed nucleus of the stria terminalis; Ce, central nucleus of the amydala; L, left hemisphere; R, right hemisphere.

aMinimum conjunction (Boolean "AND") analysis ( $p<.05$, whole-brain Šidák corrected, $k \geq 80 \mathrm{~mm}^{3}$ ).

${ }^{\mathrm{b}}$ Area $10 \mathrm{r} / \mathrm{m}$ as described by Ongur et al. (2003).

the intercept in regression models, equivalent to a single-sample $t$ test ( $t>5.47, p<.05$, whole-brain Šidák corrected for 228,483 voxels) (Birn et al., 2014; Oler et al., 2010; Šidák, 1967). At this threshold, clusters of negative connectivity were only identified in regions of deep white matter and gray matter adjacent to ventricles and, so, are neither reported nor interpreted. A minimum conjunction (Boolean "AND") was used to identify regions showing significant coupling with both seeds (Nichols, Brett, Andersson, Wager, \& Poline, 2005) and a paired $t$ test was used to assess differential functional connectivity. For ease of interpretation, differential connectivity was only examined in the subset of 12,004 voxels where functional connectivity was significant for one or both seeds $(t>4.80, p<.05$, Šidák corrected for the 12,004 voxel region-of-interest). This approach circumvents the need to interpret significant differences (e.g., BST $>\mathrm{Ce}$ ) in regions where neither seed shows significant functional connectivity. For both analyses, we imposed an arbitrary $80 \mathrm{~mm}^{3}$ (i.e., 10 native EPI voxels) minimum-extent criterion-in addition to the intensity-based thresholds ( $p<.05$, Šidák corrected)to suppress noise. Exploratory analyses yielded no reliable sex differences in Ce or BST functional connectivity. As an additional check on the integrity of the data and our approach, we confirmed our ability to identify the default mode network (Supporting Information, Figure S7). Clusters were labeled using a combination of the Mai and Harvard-Oxford atlases (Desikan et al., 2006; Frazier et al., 2005; Goldstein et al., 2007; Mai, Majtanik, \& Paxinos, 2015; Makris et al., 2006). Some figures were created using MRIcron (http://people.cas.sc.edu/rorden/mricron).

\section{3 | RESULTS}

\section{1 | Subcortical regions}

As shown in Figure 2 and Supporting Information, Figure S8, wholebrain regression analyses revealed robust coupling between the BST and the Ce regions ( $p<.05$, whole-brain Šidák corrected; Tables 2-4). Analyses seeded in the BST showed significant functional connectivity with neighboring regions of the basal forebrain and basal ganglia and distal voxels in the region of the Ce. The complementary pattern was observed for the $\mathrm{Ce}$ seed-significant functional connectivity with neighboring regions of the dorsal amygdala and with distal voxels located in the region of the BST. Consistent with invasive tracing studies (Oler et al., 2017), the BST and Ce also showed robust coupling
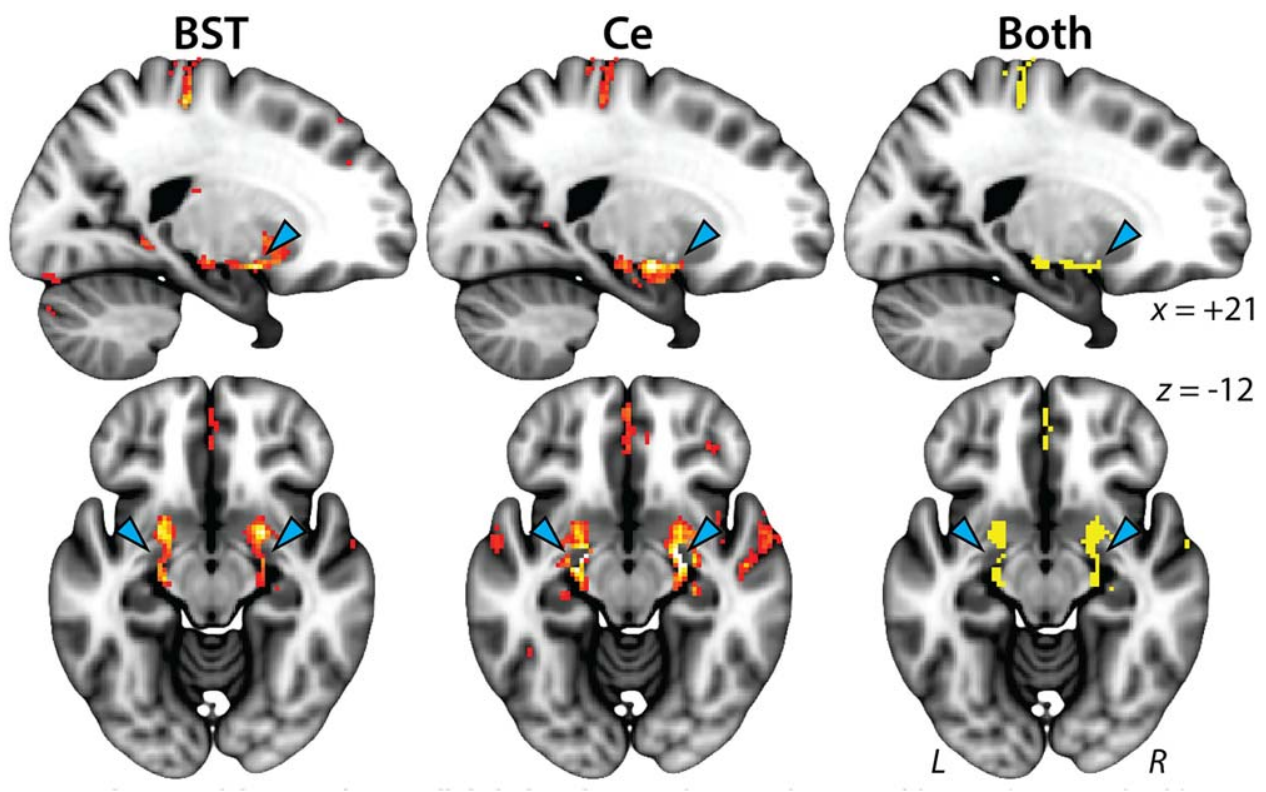

FIGURE 3 The BST and the Ce are functionally linked via the SLEA. Clusters in the region of the SLEA (cyan arrowheads). Conventions are similar to Figure 2. Abbreviations: BST = bed nucleus of the stria terminalis; $\mathrm{Ce}=$ central nucleus of the amygdala; $\mathrm{L}=$ left hemisphere;

$\mathrm{R}=$ right hemisphere; SLEA = sublenticular extended amygdala. See Figures 2 and 5 for additional views of these contrasts [Color figure can be viewed at wileyonlinelibrary.com] 
with anatomically intermediate voxels located in the SLEA, the ribbon of subcortical gray matter (substantia innominata) encompassing the ventral amygdalofugal pathway (Figure 3). Finally, both seeds showed

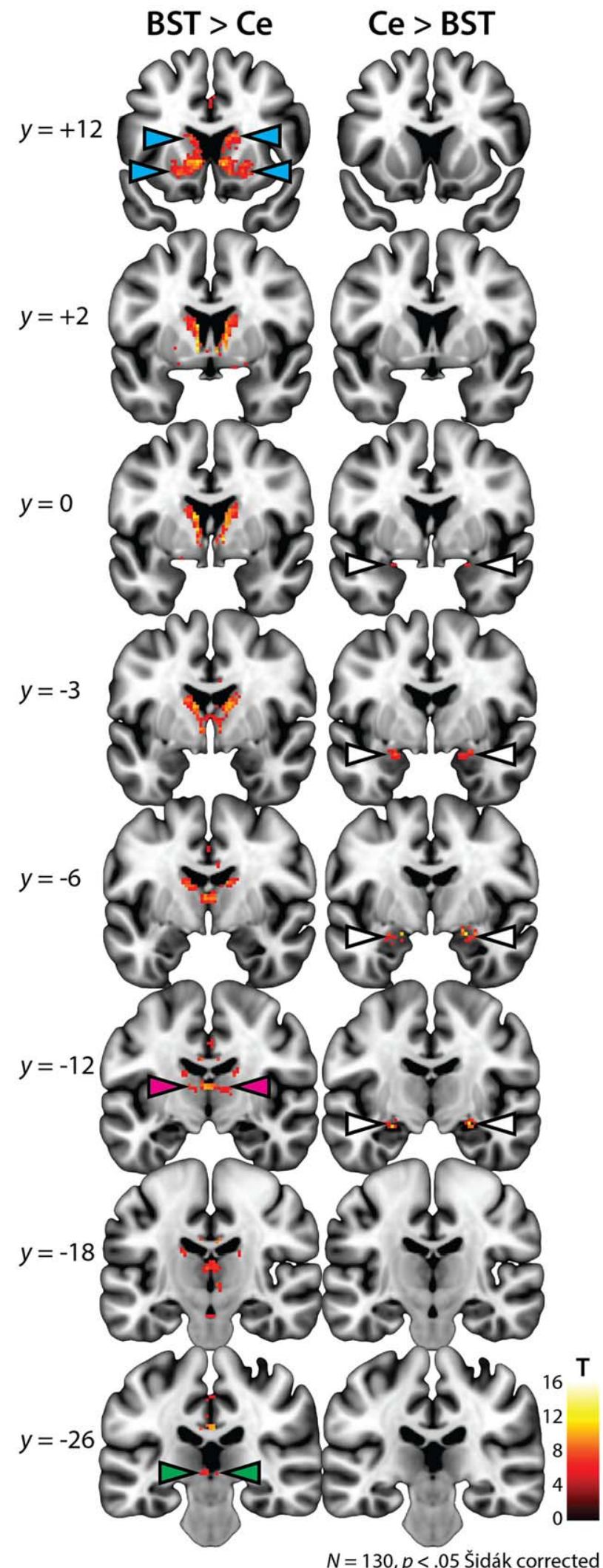

FIGURE 4. significant functional connectivity with the amygdalohippocampal area and anterior hippocampus (Figure 2).

Compared to the $\mathrm{Ce}$, the BST showed significantly stronger coupling with several subcortical regions, including the basal ganglia (i.e., nucleus accumbens, caudate, and putamen), thalamus, and the brainstem in the region of the dorsal periaqueductal gray (PAG) (Figure 4, Supporting Information, Figure S9, and Table 5). The only subcortical regions showing stronger functional connectivity with the Ce were located in the dorsal amygdala and anterior hippocampus, and included the amygdalohippocampal area and basolateral, basomedial, cortical, and medial nuclei.

\section{2 | Cortical regions}

As shown in Figures 2 and 5, the BST and the Ce showed significant functional connectivity with several cortical regions, including the ventromedial prefrontal cortex (vmPFC), posterior MCC, posterior insula, posterior cingulate/precuneus, and parts of the ventral visual processing stream (e.g., superior temporal sulcus, fusiform cortex) (Tables 2-4). As shown in Figure 5 , relative to the $\mathrm{Ce}$, the BST displayed significantly stronger coupling with a cluster centered on the anterior MCC that extends into the pregenual anterior cingulate cortex (pgACC) and vmPFC (Figure 5, farright panels, and Table 5). As detailed in the Supporting Information, Figure $\mathrm{S} 10$, control analyses indicated that these effects could not be attributed to regional differences in signal quality, as indexed by several widely used metrics (e.g., the temporal signal-to-noise ratio [tSNR]).

\section{4 | DISCUSSION}

The EAc plays a central role in assembling states of fear and anxiety and is implicated in the development, maintenance, and recurrence of a

FIGURE 4 Differential functional connectivity of the BST versus Ce. Results of a paired $t$ test comparing the intrinsic functional connectivity of the BST and Ce. The left and right columns depict regions showing significantly stronger coupling with the BST and $\mathrm{Ce}$, respectively. For ease of interpretation, differences were only examined in the subset of 12,004 voxels, where functional connectivity was significant for the BST, the Ce, or both seeds (Figures 2 and 3). Consistent with other analyses, results were thresholded at $p<.05$ Šidák corrected for the extent of the 12,004-voxel mask. Results revealed significantly stronger coupling between the BST and the basal ganglia, including the caudate, putamen, and nucleus accumbens (cyan arrowheads). The BST also showed significantly stronger connectivity with the thalamus (magenta arrowheads) and a region of the brainstem consistent with the dorsal periaqueductal gray (green arrowheads; see also Supporting Information, Figure S9). The only regions showing stronger connectivity with the Ce were neighboring regions of the amygdala (white arrowheads), including voxels in the region of the amygdalohippocampal area, anterior hippocampus (not depicted) and the basolateral, basomedial, cortical, and medial nuclei. Note: Results are depicted here and reported in the accompanying tables for clusters of at least $80 \mathrm{~mm}^{3}$. See Figure 5 for additional views of the BST > Ce contrast. Abbreviations: BST = bed nucleus of the stria terminalis; $\mathrm{Ce}=$ central nucleus of the amygdala; $\mathrm{L}=$ left hemisphere; $\mathrm{R}=$ right hemisphere [Color figure can be viewed at wileyonlinelibrary.com] 
TABLE 5 Regions showing significant differences in intrinsic functional connectivity between the BST and the $\mathrm{Ce}^{\mathrm{a}}$

\begin{tabular}{|c|c|c|c|c|c|c|c|}
\hline Effect & $x$ & y & $z$ & $t$ & $\mathrm{~mm}^{3}$ & Hemisphere & Region(s)/subregions \\
\hline \multirow[t]{19}{*}{$\mathrm{BST}>\mathrm{Ce}$} & -25 & 55 & 31 & 6.8 & 80 & $\mathrm{~L}$ & Frontal pole: BA9/BA10 \\
\hline & 2 & 45 & -1 & 8.43 & 344 & B & $\begin{array}{l}\text { Ventromedial prefrontal cortex: OP } 10 \mathrm{r} / \mathrm{m}^{\mathrm{b}} \text {; } \\
\text { inferior frontopolar gyrus; rostral gyrus; } \\
\text { anterior cingulate, pregenual }\end{array}$ \\
\hline & 21 & 41 & 31 & 7.12 & 96 & $\mathrm{R}$ & Superior frontal sulcus, anterior \\
\hline & -25 & 41 & 35 & 5.69 & 112 & $\mathrm{~L}$ & Superior frontal sulcus, anterior \\
\hline & 11 & 37 & -3 & 7.11 & 96 & $\mathrm{R}$ & Cingulate: cingulate sulcus, pregenual \\
\hline & 7 & 36 & 25 & 9.94 & 3,504 & B & $\begin{array}{l}\text { Cingulate: cingulate sulcus, pregenual; cingu- } \\
\text { late sulcus, anterior midcingulate }\end{array}$ \\
\hline & 49 & 23 & -9 & 7.53 & 80 & $\mathrm{R}$ & Orbitofrontal cortex: OP47, Basal operculum \\
\hline & 6 & 5 & -2 & 17.15 & 10,472 & B & $\begin{array}{l}\text { Basal forebrain: caudate, putamen, globus } \\
\text { pallidus, nucleus accumbens, rostrodorsal } \\
\text { hypothalamus, sublenticular extended } \\
\text { amygdala (ventral amygdalofugal pathway), } \\
\text { thalamus }\end{array}$ \\
\hline & 3 & -11 & 35 & 6.73 & 128 & $\mathrm{R}$ & Posterior cingulate \\
\hline & -1 & -17 & -21 & 7.06 & 80 & $\mathrm{~L}$ & $\begin{array}{l}\text { Brainstem ventral to the interpeduncular cis- } \\
\text { tern }\end{array}$ \\
\hline & -3 & -23 & -1 & 7.34 & 112 & $\mathrm{~L}$ & Periaqueductal gray, dorsolateral \\
\hline & 5 & -24 & -3 & 8.38 & 136 & $\mathrm{R}$ & Periaqueductal gray, dorsolateral \\
\hline & 3 & -27 & 25 & 10.17 & 968 & B & Posterior cingulate \\
\hline & 4 & -35 & 47 & 8.45 & 800 & B & Posterior cingulate \\
\hline & 13 & -47 & 31 & 5.94 & 104 & $\mathrm{R}$ & Posterior cingulate \\
\hline & -7 & -69 & 33 & 8.82 & 288 & $\mathrm{~L}$ & Precuneus \\
\hline & 1 & -75 & 43 & 6.89 & 232 & B & Precuneus \\
\hline & -8 & -81 & 3 & 6.86 & 216 & $\mathrm{~L}$ & Calcarine sulcus \\
\hline & 9 & -87 & 1 & 7.59 & 488 & $\mathrm{R}$ & Calcarine sulcus \\
\hline \multirow[t]{2}{*}{$\mathrm{Ce}>\mathrm{BST}$} & 25 & -9 & -15 & -14.31 & 536 & $\mathrm{R}$ & $\begin{array}{l}\text { Anterior hippocampus and amygdala: amygda- } \\
\text { lohippocampal area, anterior hippocampus, } \\
\text { basolateral, basomedial, cortical, medial }\end{array}$ \\
\hline & -21 & -10 & -15 & -11.19 & 504 & $\mathrm{~L}$ & $\begin{array}{l}\text { Amygdala: amygdalohippocampal area, anterior } \\
\text { hippocampus, basolateral, basomedial, corti- } \\
\text { cal, medial }\end{array}$ \\
\hline
\end{tabular}

Note. Abbreviations: B, bilateral; BST, bed nucleus of the stria terminalis; Ce, central nucleus of the amygdala; L, left hemisphere; R, right hemisphere. ${ }^{a}$ Paired $t$ test for the subset of 12,004 voxels showing significant functional connectivity with the BST, Ce, or both seeds $(p<.05$, Šidák corrected for the extent of the 12,004-voxel mask).

${ }^{\mathrm{b}}$ Area $10 \mathrm{r} / \mathrm{m}$ as described by Ongur et al. (2003).

range of debilitating psychiatric disorders. The present findings provide new insights into the normative architecture of the EAc functional network. Our results indicate that the BST and the Ce are robustly interconnected via the SLEA (Figure 3 and Supporting Information, Figure S8), consistent with anatomical and functional tracing studies in monkeys (Birn et al., 2014; Oler et al., 2012, 2017). By and large, the BST and the Ce showed patterns of functional connectivity that were similar to one another and concordant with prior human imaging research (Table 6). Both regions showed significant coupling with subcortical and cortical regions implicated in fear and anxiety-including the anterior hippocampus, insula, MCC, and vmPFC (Figures 2 and 5)-reinforcing the hypothesis that these regions represent a functionally coherent macro-circuit (Alheid \& Heimer, 1988; Fox et al., 2015a; Fudge et al., 2017; Oler et al., 2012; Shackman \& Fox, 2016; Fox \& Shackman, in press).

Despite their many similarities, it is unlikely that the BST and the Ce are interchangeable (Fox \& Shackman, ; Shackman \& Fox, 2016). Indeed, the BST showed significantly stronger connectivity with anterior cortical regions (anterior MCC, pgACC, and vmPFC), with the posterior cingulate/precuneus, with the medial temporal lobe (striatum and SLEA), and with the brainstem in the region of the dorsal PAG (Supporting Information, Figure S9), whereas the Ce showed stronger connectivity with neighboring regions of the amygdala, amygdalohippocampal area, and anterior hippocampus (Figures 4 and 


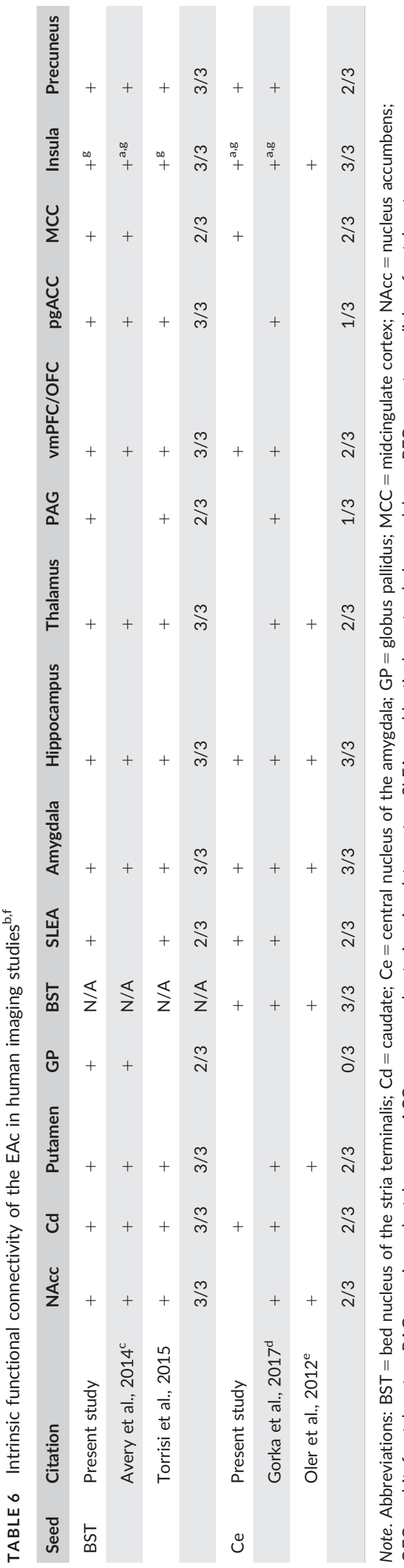

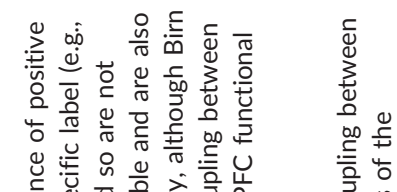

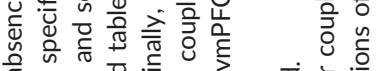

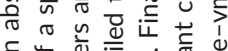
这 运

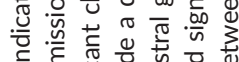

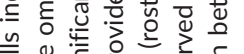

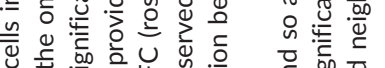

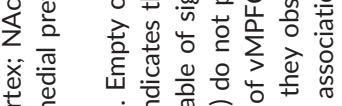



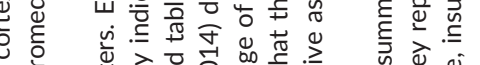

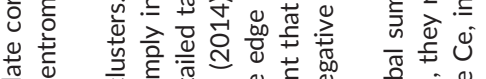







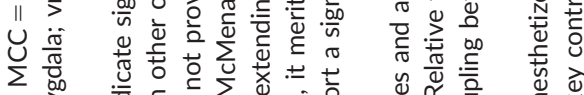

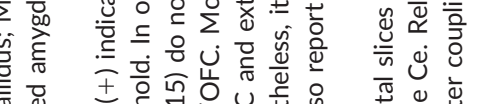

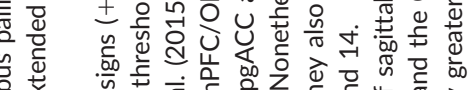

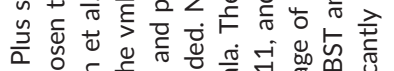

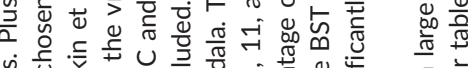

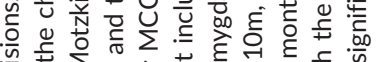

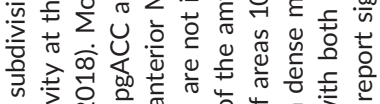

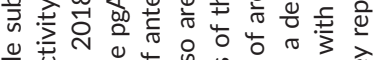

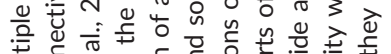

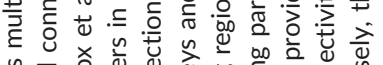



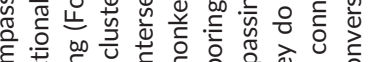



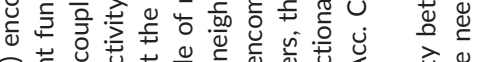

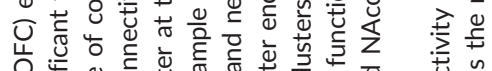

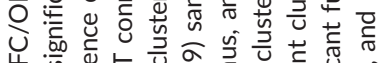

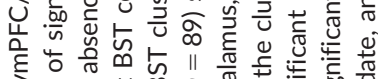




竞

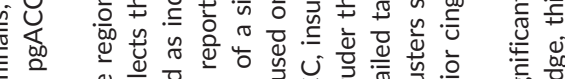

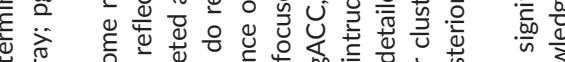
它

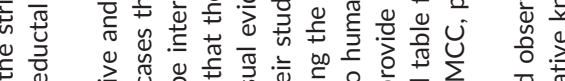

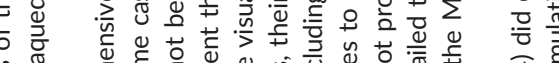

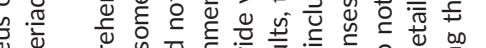

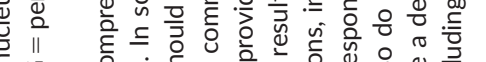



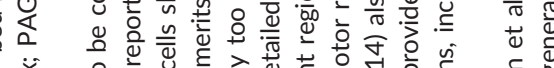



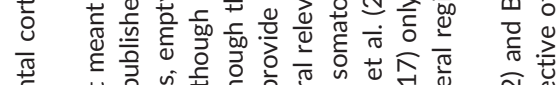

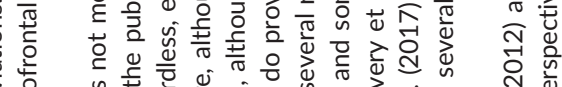



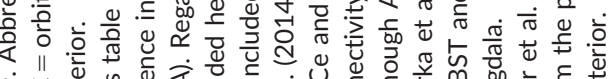

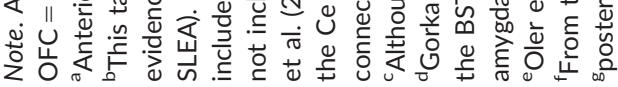




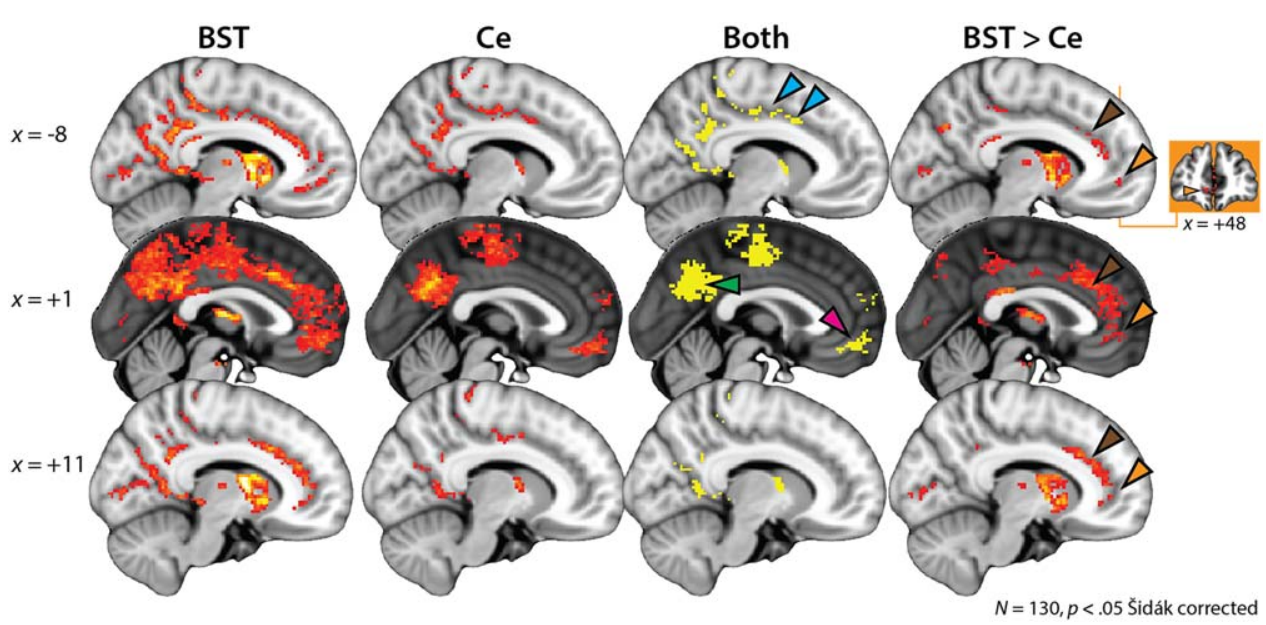

FIGURE 5 Intrinsic functional connectivity of the EAc and midline cortical regions. The first two columns depict the results of whole-brain regression analyses for the BST and Ce seed regions, respectively $(p<.05$, whole-brain Šidák corrected). The third column depicts the intersection (Boolean "AND") of the two thresholded maps. The fourth column depicts the results of a paired $t$ test comparing the intrinsic functional connectivity of the BST and Ce ( $p<.05$, small-volume Šidák corrected). Both seeds show significant functional connectivity with the posterior cingulate/precuneus (green arrowhead), posterior MCC (cyan arrowheads), and vmPFC (magenta arrowhead). Relative to the Ce, the BST shows significantly stronger coupling with the anterior MCC and pgACC (brown arrowheads) and the vmPFC (orange arrowheads). Orange inset depicts a coronal slice through the vmPFC cluster, which extends along the rostral-caudal axis from area $10 \mathrm{r} / \mathrm{m}$ and the inferior frontopolar gyrus to the rostral gyrus and pgACC. Conventions are similar to Figure 2 (first three columns) and Figure 4 (fourth column). See Figures 2-4 for additional views of these contrasts. Abbreviations: BST = bed nucleus of the stria terminalis; $\mathrm{Ce}=\mathrm{central}$ nucleus of the amygdala; $E A c=$ central divisions of the extended amygdala; $L=$ left hemisphere; $M C C=$ midcingulate cortex; $\operatorname{pgACC}=$ pregenual anterior cingulate cortex; $\mathrm{R}=$ right hemisphere; $\mathrm{vmPFC}=$ ventromedial prefrontal cortex [Color figure can be viewed at wileyonlinelibrary.com]

5)-observations that largely align with recent high-resolution fMRI research (Gorka et al., 2017) (cf. Table 1). Supplementary analyses indicated that these effects were not a consequence of regional differences in signal quality (e.g., tSNR).

We also observed significant coupling between the BST, the Ce, and the vmPFC (i.e., inferior frontopolar gyrus, rostral gyrus, and area OP10), although this effect was stronger for the BST seed region (Figure 5). This pattern is consistent with other work leveraging the enhanced resolution afforded by 7T fMRI (Gorka et al., 2017; their figure 2e) and is particularly interesting in light of several recent observations in nonhuman primate models of fear and anxiety. First, intrinsic coupling between the $\mathrm{Ce}$ and vmPFC covaries with the intensity of defensive behaviors and neuroendocrine activity elicited by exposure to human intruder threat in monkeys (Birn et al., 2014). Second, metabolic activity in the Ce, BST, and VmPFC, as well as the anterior hippocampus and PAG, covaries with these same anxiety-related responses (Fox et al., 2015b). Third, vmPFC lesions have been shown to reduce these defensive responses and imaging research suggests that this anxiolytic effect is likely to be mediated by "downstream" alterations in BST metabolism (Fox et al., 2010; Kalin, Shelton, \& Davidson, 2007; Motzkin et al., 2015; Rudebeck, Saunders, Prescott, Chau, \& Murray, 2013). These and other observations (e.g., Grayson et al., 2016; Kalin et al., 2004, 2016; Meyer et al., 2017; Mobbs et al., 2007, 2009, 2010) motivate the hypothesis that fear and anxiety partially reflect a core neural system encompassing the BST, Ce, vmPFC, anterior hippocampus, and PAG (Fox et al., 2015b; Oler et al., 2016; Shackman et al., 2016b).

Our results revealed evidence of robust coupling between the $\mathrm{BST}, \mathrm{Ce}$, and rostral cingulate and they hint at a rostro-caudal gradient: both seeds showed coupling with the posterior MCC, while the BST showed significantly stronger coupling with a cluster centered on the anterior MCC (Figure 5). Notably, the MCC and a region consistent with the BST are frequently co-activated in imaging studies of Pavlovian fear conditioning (Fullana et al., 2016; Mechias, Etkin, \& Kalisch, 2010) and uncertain threat anticipation (Alvarez et al., 2011, 2015; Choi et al., 2012; Grupe et al., 2013; Herrmann et al., 2016; Klumpers et al., 2015; McMenamin et al., 2014; Meyer et al., 2017; Somerville et al., 2010). We have previously hypothesized that the MCC uses information about pain, negative feedback, punishment, and threat to bias responding in situations where the optimal course of action is uncertain or risky (Cavanagh \& Shackman, 2015; Shackman et al., 2011) (see also de la Vega et al., 2016) and the present results highlight the potential importance of communication between the MCC and the EAc, particularly the BST, for this kind of adaptive control. A key challenge for future research will be to more formally characterize the nature of task-related interactions among these three key regions using graph-theoretic or related analytic techniques (McMenamin et al., 2014; Najafi et al., 2017).

Clearly, a number of other important challenges remain. As with most brain imaging studies, our analyses do not permit mechanistic inferences and like other studies focused on functional connectivity, our conclusions are tempered by questions about the origins and significance of correlated fluctuations in the blood-oxygen-level-dependent (BOLD) fMRI signal (Akam \& Kullmann, 2014; Cabral, Kringelbach, \& Deco, 2014; Logothetis, 2008). A key challenge for future research will be to use a combination of mechanistic (e.g., optogenetic) and wholebrain imaging techniques to clarify the specific causal contributions of 
the regions highlighted here and more precisely delineate the nature of their functional interactions (Fox \& Shackman, in press; Shackman \& Fox, 2016; Wiegert, Mahn, Prigge, Printz, \& Yizhar, 2017).

Existing treatments for anxiety disorders are inconsistently effective or associated with significant adverse effects (Bystritsky, 2006; Cloos \& Ferreira, 2009; Craske et al., 2017; Cuijpers, Cristea, Karyotaki, Reijnders, \& Huibers, 2016; James, James, Cowdrey, Soler, \& Choke, 2015), highlighting the need to identify and understand the neural mechanisms controlling the experience and expression of fear and anxiety. Building on prior mechanistic and imaging research, the present study indicates that the BST and the Ce are marked by broadly similar patterns of intrinsic functional connectivity, with both regions showing significant coupling with the EAc, anterior hippocampus, insula, MCC, and vmPFC. Despite these similarities, the BST displayed significantly stronger connectivity with the rostral cingulate and vmPFC. These observations provide a baseline against which to compare a range of special populations-including individuals at risk for developing mental illness and patients suffering from psychiatric disorders-and inform our understanding of the role of the EAc in normal and pathological fear and anxiety. The use of a relatively large sample increases our confidence in the robustness of these results (Cremers, Wager, \& Yarkoni, 2017; Fox, Lapate, Davidson, \& Shackman, 2018; Poldrack et al., 2017). Finally, from a methodological perspective, these results highlight the value of several new techniques for EAc seed prescription and image registration/normalization. The former is likely to be useful for other investigators focused on the BST and Ce, while the latter will be advantageous for any investigator confronted with the problem of spatially normalizing structural images that have been modified-anatomically "anonymized" or "de-identified"-prior to public release (Holmes et al., 2015; Nooner et al., 2012).

\section{5 | CONTRIBUTIONS}

R.M.T, A.J.S., and J.F.S. designed the study. M.D.S. coordinated data extraction. B.M.N. developed and implemented the protocol for segmenting the Ce seed and the HyperEdge method. J.F.S. developed and implemented the novel image registration/normalization pipeline. R.M. T. and J.F.S. processed data. J.F.S. and A.J.S. analyzed data. R.M.T., A.J. S., and A.S.F. interpreted data. R.M.T., A.J.S., A.S.F., and B.M.N. wrote the article. A.J.S., R.M.T., B.M.N., and A.S.F. created figures. R.M.T. and A.J.S. created tables. S.T. provided theoretical guidance. A.J.S. funded and supervised all aspects of the study. All authors contributed to reviewing and revising the article and approved the final version.

\section{ACKNOWLEDGMENTS}

Authors acknowledge assistance from J. Blackford, K. DeYoung, L. Friedman, M. Milham, and D. Tromp and critical feedback from N. Fox, L. Pessoa, and E. Redcay. They also wish to thank Drs R. Poldrack and A. Holmes for guidance on the signal quality analyses. This work was supported by the University of California, Davis; University of Maryland, College Park; University of Wisconsin-
Madison; and National Institutes of Health (DA040717 and $\mathrm{MH107444).} \mathrm{Authors} \mathrm{declare} \mathrm{no} \mathrm{conflicts} \mathrm{of} \mathrm{interest.}$

\section{DATA AVAILABILITY/SHARING}

Key statistical maps are available in NeuroVault.org. Raw data are publicly available (http://fcon_1000.projects.nitrc.org/indi/enhanced/).

\section{ORCID}

Alexander J. Shackman (D) http://orcid.org/0000-0002-3629-4704

\section{REFERENCES}

Acosta-Cabronero, J., Williams, G. B., Pereira, J. M., Pengas, G., \& Nestor, P. J. (2008). The impact of skull-stripping and radio-frequency bias correction on grey-matter segmentation for voxel-based morphometry. Neuroimage, 39, 1654-1665.

Akam, T., \& Kullmann, D. M. (2014). Oscillatory multiplexing of population codes for selective communication in the mammalian brain. Nature Reviews Neuroscience, 15, 111-122.

Alheid, G. F., \& Heimer, L. (1988). New perspectives in basal forebrain organization of special relevance for neuropsychiatric disorders: the striatopallidal, amygdaloid, and corticopetal components of substantia innominata. Neuroscience, 27, 1-39.

Alvarez, R. P., Chen, G., Bodurka, J., Kaplan, R., \& Grillon, C. (2011). Phasic and sustained fear in humans elicits distinct patterns of brain activity. Neurolmage, 55, 389-400.

Alvarez, R. P., Kirlic, N., Misaki, M., Bodurka, J., Rhudy, J. L., Paulus, M. P., \& Drevets, W. C. (2015). Increased anterior insula activity in anxious individuals is linked to diminished perceived control. Translational Psychiatry, 5, e591.

Amano, K., Tanikawa, T., Kawamura, H., Iseki, H., Notani, M., Kawabatake, H., ... Kitamura, K. (1982). Endorphins and pain relief. Further observations on electrical stimulation of the lateral part of the periaqueductal gray matter during rostral mesencephalic reticulotomy for pain relief. Applied Neurophysiology, 45, 123-135.

Amunts, K., Kedo, O., Kindler, M., Pieperhoff, P., Mohlberg, H., Shah, N. J., ... Zilles, K. (2005). Cytoarchitectonic mapping of the human amygdala, hippocampal region and entorhinal cortex: intersubject variability and probability maps. Anatomy and Embryology, 210, 343352.

Antoniadis, E. A., Winslow, J. T., Davis, M., \& Amaral, D. G. (2007). Role of the primate amygdala in fear-potentiated startle: effects of chronic lesions in the rhesus monkey. Journal of Neuroscience, 27(28), 73867396.

Ashburner, J., \& Friston, K. J. (2005). Unified segmentation. Neurolmage, 26, 839-851.

Assareh, N., Sarrami, M., Carrive, P., \& McNally, G. P. (2016). The organization of defensive behavior elicited by optogenetic excitation of rat lateral or ventrolateral periaqueductal gray. Behavioral Neuroscience, 130, 406-414

Avants, B. B., Epstein, C. L., Grossman, M., \& Gee, J. C. (2008). Symmetric diffeomorphic image registration with cross-correlation: Evaluating automated labeling of elderly and neurodegenerative brain. Medical Image Analysis, 12, 26-41.

Avants, B. B., Tustison, N. J., Song, G., Cook, P. A., Klein, A., \& Gee, J. C. (2011). A reproducible evaluation of ANTs similarity metric performance in brain image registration. Neuroimage, 54, 2033-2044. 
Avants, B. B., Yushkevich, P., Pluta, J., Minkoff, D., Korczykowski, M., Detre, J., \& Gee, J. C. (2010). The optimal template effect in hippocampus studies of diseased populations. Neuroimage, 49, 2457-2466.

Avery, S. N., Clauss, J. A., \& Blackford, J. U. (2016). The human BNST: Functional role in anxiety and addiction. Neuropsychopharmacology : Official Publication of the American College of Neuropsychopharmacology, 41, 126-141.

Avery, S. N., Clauss, J. A., Winder, D. G., Woodward, N., Heckers, S., \& Blackford, J. U. (2014). BNST neurocircuitry in humans. Neurolmage, 91, 311-323.

Bandler, R., Price, J. L., \& Keay, K. A. (2000). Brain mediation of active and passive emotional coping. Progress in Brain Research, 122, 333349.

Banihashemi, L., Sheu, L. K., Midei, A. J., \& Gianaros, P. J. (2015). Childhood physical abuse predicts stressor-evoked activity within central visceral control regions. Social Cognitive and Affective Neuroscience, 10, 474-485.

Bechara, A., Tranel, D., Damasio, H., Adolphs, R., Rockland, C., \& Damasio, A. R. (1995). Double dissociation of conditioning and declarative knowledge relative to the amygdala and hippocampus in humans. Science, 269, 1115-1118.

Behzadi, Y., Restom, K., Liau, J., \& Liu, T. T. (2007). A component based noise correction method (CompCor) for BOLD and perfusion based fMRI. Neuroimage, 37, 90-101.

Birn, R. M., Shackman, A. J., Oler, J. A., Williams, L. E., McFarlin, D. R., Rogers, G. M., ... Kalin, N. H. (2014). Evolutionarily conserved dysfunction of prefrontal-amygdalar connectivity in early-life anxiety. Molecular Psychiatry, 19, 915-922.

Biswal, B., Yetkin, F. Z., Haughton, V. M., \& Hyde, J. S. (1995). Functional connectivity in the motor cortex of resting human brain using echoplanar MRI. Magnetic Resonance in Medicine, 34, 537-541.

Brinkmann, L., Buff, C., Feldker, K., Neumeister, P., Heitmann, C. Y., Hofmann, D., ... Straube, T. (2018). Inter-individual differences in trait anxiety shape the functional connectivity between the bed nucleus of the stria terminalis and the amygdala during brief threat processing. Neuroimage, 166, 110-116.

Brinkmann, L., Buff, C., Feldker, K., Tupak, S. V., Becker, M. P. I., Herrmann, M. J., \& Straube, T. (2017a). Distinct phasic and sustained brain responses and connectivity of amygdala and bed nucleus of the stria terminalis during threat anticipation in panic disorder. Psychological Medicine, 47, 2675-2688.

Brinkmann, L., Buff, C., Neumeister, P., Tupak, S. V., Becker, M. P., Herrmann, M. J., \& Straube, T. (2017b). Dissociation between amygdala and bed nucleus of the stria terminalis during threat anticipation in female post-traumatic stress disorder patients. Human Brain Mapping, 38, 2190-2205.

Buff, C., Brinkmann, L., Bruchmann, M., Becker, M. P. I., Tupaka, S., Herrmann, M. J., \& Straube, T. (2017). Activity alterations in the bed nucleus of the stria terminalis and amygdala during threat anticipation in Generalized Anxiety Disorder. Social Cognitive and Affective Neuroscience, 12, 1766-1774.

Buhle, J. T., Silvers, J. A., Wager, T. D., Lopez, R., Onyemekwu, C., Kober, H., ... Ochsner, K. N. (2014). Cognitive reappraisal of emotion: A meta-analysis of human neuroimaging studies. Cerebral Cortex, 24, 2981-2990.

Bystritsky, A. (2006). Treatment-resistant anxiety disorders. Molecular Psychiatry, 11, 805-814.

Cabral, J., Kringelbach, M. L., \& Deco, G. (2014). Exploring the network dynamics underlying brain activity during rest. Progress in Neurobiology, 114C, 102-131.
Calhoon, G. G., \& Tye, K. M. (2015). Resolving the neural circuits of anxiety. Nature Neuroscience, 18, 1394-1404.

Carrive, P., \& Morgan, M. M. (2012). Periaqueductal gray. In J. K. Mai \& G. Paxinos (Eds.), The human nervous system (3rd ed., pp. 367-400. New York: Academic Press.

Cavanagh, J. F., \& Shackman, A. J. (2015). Frontal midline theta reflects anxiety and cognitive control: Meta-analytic evidence. Journal of Physiology, Paris, 109, 3-15.

Chang, L. J., Gianaros, P. J., Manuck, S. B., Krishnan, A., \& Wager, T. D. (2015). A sensitive and specific neural signature for picture-induced negative affect. PLoS Biology, 13, e1002180.

Chen, S., Zhou, H., Guo, S., Zhang, J., Qu, Y., Feng, Z., ... Zheng, X. (2015). Optogenetics based rat-robot control: Optical stimulation encodes "stop" and "escape" commands. Annals of Biomedical Engineering, 43, 1851-1864.

Cheng, D. T., Knight, D. C., Smith, C. N., \& Helmstetter, F. J. (2006). Human amygdala activity during the expression of fear responses. Behavioral Neuroscience, 120, 1187-1195.

Cheng, D. T., Richards, J., \& Helmstetter, F. J. (2007). Activity in the human amygdala corresponds to early, rather than late period autonomic responses to a signal for shock. Learning \& Memory, 14, 485-490.

Choi, J. M., Padmala, S., \& Pessoa, L. (2012). Impact of state anxiety on the interaction between threat monitoring and cognition. Neurolmage, 59, 1912-1923.

Choi, J. S., \& Kim, J. J. (2010). Amygdala regulates risk of predation in rats foraging in a dynamic fear environment. Proceedings of the National Academy of Sciences of the United States of America, 107, 21773-21777.

Ciocchi, S., Herry, C., Grenier, F., Wolff, S. B., Letzkus, J. J., Vlachos, I., ... Luthi, A. (2010). Encoding of conditioned fear in central amygdala inhibitory circuits. Nature, 468, 277-282.

Cloos, J. M., \& Ferreira, V. (2009). Current use of benzodiazepines in anxiety disorders. Current Opinion in Psychiatry, 22(1), 90-95.

Costafreda, S. G., Brammer, M. J., David, A. S., \& Fu, C. H. (2008). Predictors of amygdala activation during the processing of emotional stimuli: a meta-analysis of 385 PET and fMRI studies. Brain Research Reviews, 58, 57-70.

Coulombe, M. A., Erpelding, N., Kucyi, A., \& Davis, K. D. (2016). Intrinsic functional connectivity of periaqueductal gray subregions in humans. Human Brain Mapping, 37, 1514-1530.

Cox, R. W. (1996). AFNI: Software for analysis and visualization of functional magnetic resonance neuroimages. Computers and Biomedical Research, 29, 162-173.

Craske, M. G., Stein, M. B., Eley, T. C., Milad, M. R., Holmes, A., Rapee, R. M., \& Wittchen, H. U. (2017). Anxiety disorders. Nature Reviews. Disease Primers, 3, 17024.

Cremers, H. R., Wager, T. D., \& Yarkoni, T. (2017). The relation between statistical power and inference in fMRI. PLoS One, 12, e0184923.

Cuijpers, P., Cristea, I. A., Karyotaki, E., Reijnders, M., \& Huibers, M. J. (2016). How effective are cognitive behavior therapies for major depression and anxiety disorders? A meta-analytic update of the evidence. World Psychiatry, 15, 245-258.

Davis, M., Walker, D. L., Miles, L., \& Grillon, C. (2010). Phasic vs sustained fear in rats and humans: Role of the extended amygdala in fear vs anxiety. Neuropsychopharmacology : Official Publication of the American College of Neuropsychopharmacology, 35, 105-135.

Davis, M., \& Whalen, P. J. (2001). The amygdala: vigilance and emotion. Molecular Psychiatry, 6, 13-34.

de la Vega, A., Chang, L. J., Banich, M. T., Wager, T. D., \& Yarkoni, T. (2016). Large-scale meta-analysis of human medial frontal cortex 
reveals tripartite functional organization. The Journal of Neuroscience, 36, 6553-6562

deCampo, D. M., \& Fudge, J. L. (2013). Amygdala projections to the lateral bed nucleus of the stria terminalis in the macaque: comparison with ventral striatal afferents. Journal of Comparative Neurology, 521, 3191-3216.

Desikan, R. S., Ségonne, F., Fischl, B., Quinn, B. T., Dickerson, B. C., Blacker, D., ... Killiany, R. J. (2006). An automated labeling system for subdividing the human cerebral cortex on MRI scans into gyral based regions of interest. Neuroimage, 31, 968-980.

DiLuca, M., \& Olesen, J. (2014). The cost of brain diseases: a burden or a challenge?. Neuron, 82, 1205-1208.

Ehrlich, I., Humeau, Y., Grenier, F., Ciocchi, S., Herry, C., \& Luthi, A. (2009). Amygdala inhibitory circuits and the control of fear memory. Neuron, 62, 757-771.

Entis, J. J., Doerga, P., Barrett, L. F., \& Dickerson, B. C. (2012). A reliable protocol for the manual segmentation of the human amygdala and its subregions using ultra-high resolution MRI. Neuroimage, 60, 1226-1235.

Fadok, J. P., Krabbe, S., Markovic, M., Courtin, J., Xu, C., Massi, L., ... Luthi, A. (2017). A competitive inhibitory circuit for selection of active and passive fear responses. Nature, 542, 96-100.

Faull, O. K., \& Pattinson, K. T. (2017). The cortical connectivity of the periaqueductal gray and the conditioned response to the threat of breathlessness. Elife, 6 ,

Fein, G., Landman, B., Tran, H., Barakos, J., Moon, K., Di Sclafani, V., \& Shumway, R. (2006). Statistical parametric mapping of brain morphology: sensitivity is dramatically increased by using brain-extracted images as inputs. Neuroimage, 30, 1187-1195.

Feinstein, J. S., Adolphs, R., Damasio, A., \& Tranel, D. (2011). The human amygdala and the induction and experience of fear. Current Biology, 21, 1-5.

Feinstein, J. S., Adolphs, R., \& Tranel, D. (2016). A tale of survival from the world of Patient S.M. In D. G. Amaral \& R. Adolphs (Eds.), Living without an amygdala. New York: Guilford.

Fischmeister, F. P., Hollinger, I., Klinger, N., Geissler, A., Wurnig, M. C., Matt, E., ... Beisteiner, R. (2013). The benefits of skull stripping in the normalization of clinical fMRI data. Neuroimage. Clinical, 3, 369380.

Fox, A. S., \& Kalin, N. H. (2014). A translational neuroscience approach to understanding the development of social anxiety disorder and its pathophysiology. American Journal of Psychiatry, 171, 1162-1173.

Fox, A. S., Lapate, R. C., Davidson, R. J., \& Shackman, A. J. (2018). The nature of emotion: A research agenda for the 21st century. In A. S. Fox, R. C. Lapate, A. J. Shackman, \& R. J. Davidson (Eds.), The nature of emotion. Fundamental questions (2nd ed.). New York: Oxford University Press.

Fox, A. S., Oler, J. A., Shackman, A. J., Shelton, S. E., Raveendran, M., McKay, D. R., ... Kalin, N. H. (2015). Intergenerational neural mediators of early-life anxious temperament. Proceedings of the National Academy of Sciences Usa, 112, 9118-9122.

Fox, A. S., Oler, J. A., Tromp, D. P., Fudge, J. L., \& Kalin, N. H. (2015). Extending the amygdala in theories of threat processing. Trends in Neurosciences, 38, 319-329.

Fox, A. S., \& Shackman, A. J. in press. The central extended amygdala in fear and anxiety: Closing the gap between mechanistic and neuroimaging research. Neuroscience Letters.

Fox, A. S., Shelton, S. E., Oakes, T. R., Converse, A. K., Davidson, R. J., \& Kalin, N. H. (2010). Orbitofrontal cortex lesions alter anxiety-related activity in the primate bed nucleus of stria terminalis. Journal of Neuroscience, 30, 7023-7027.
Fox, A. S., Shelton, S. E., Oakes, T. R., Davidson, R. J., \& Kalin, N. H. (2008). Trait-like brain activity during adolescence predicts anxious temperament in primates. PLoS ONE, 3, e2570.

Fox, M. D., Snyder, A. Z., Vincent, J. L., Corbetta, M., Van Essen, D. C., \& Raichle, M. E. (2005). The human brain is intrinsically organized into dynamic, anticorrelated functional networks. Proceedings of the National Academy of Sciences of the United States of America, 102, 9673-9678.

Frazier, J. A., Chiu, S., Breeze, J. L., Makris, N., Lange, N., Kennedy, D. N., ... Biederman, J. (2005). Structural brain magnetic resonance imaging of limbic and thalamic volumes in pediatric bipolar disorder. American Journal of Psychiatry, 162, 1256-1265.

Freese, J. L., \& Amaral, D. G. (2009). Neuroanatomy of the primate amygdala. In P. J. Whalen \& E. A. Phelps (Eds.), The human amygdala (pp. 3-42. NY: Guilford.

Fudge, J. L., Kelly, E. A., Pal, R., Bedont, J. L., Park, L., \& Ho, B. (2017). Beyond the classic VTA: Extended amygdala projections to DAstriatal paths in the primate. Neuropsychopharmacology, 42, 15631576.

Fullana, M. A., Harrison, B. J., Soriano-Mas, C., Vervliet, B., Cardoner, N., Avila-Parcet, A., \& Radua, J. (2016). Neural signatures of human fear conditioning: an updated and extended meta-analysis of $\mathrm{fMRI}$ studies. Molecular Psychiatry, 21, 500-508.

Fusar-Poli, P., Placentino, A., Carletti, F., Landi, P., Allen, P., Surguladze, S., ... Politi, P. (2009). Functional atlas of emotional faces processing: a voxel-based meta-analysis of 105 functional magnetic resonance imaging studies. Journal of Psychiatry and Neuroscience, 34, 418-432.

Global Burden of Disease Collaborators. (2016). Global, regional, and national incidence, prevalence, and years lived with disability for 310 diseases and injuries, 1990-2015: a systematic analysis for the Global Burden of Disease Study 2015. Lancet, 388, 1545-1602.

Goldstein, J. M., Seidman, L. J., Makris, N., Ahern, T., O'brien, L. M., Caviness, V. S., Jr., ... Tsuang, M. T. (2007). Hypothalamic abnormalities in schizophrenia: sex effects and genetic vulnerability. Biological Psychiatry, 61, 935-945.

Goode, T. D., \& Maren, S. (2017). Role of the bed nucleus of the stria terminalis in aversive learning and memory. Learning \&Amp; Memory (Cold Spring Harbor, N.Y.), 24, 480-491.

Gorka, A. X., Torrisi, S., Shackman, A. J., Grillon, C., \& Ernst, M. (2017). Intrinsic functional connectivity of the central nucleus of the amygdala and bed nucleus of the stria terminalis. Neuroimage.

Grayson, D. S., Bliss-Moreau, E., Machado, C. J., Bennett, J., Shen, K., Grant, K. A., ... Amaral, D. G. (2016). The rhesus monkey connectome predicts disrupted functional networks resulting from pharmacogenetic inactivation of the amygdala. Neuron, 91, 453-466.

Greve, D. N., \& Fischl, B. (2009). Accurate and robust brain image alignment using boundary-based registration. Neuroimage, 48, 63-72.

Griebel, G., \& Holmes, A. (2013). 50 years of hurdles and hope in anxioIytic drug discovery. Nature Reviews. Drug Discovery, 12, 667-687.

Grupe, D. W., \& Nitschke, J. B. (2013). Uncertainty and anticipation in anxiety: an integrated neurobiological and psychological perspective. Nature Reviews Neuroscience, 14, 488-501.

Grupe, D. W., Oathes, D. J., \& Nitschke, J. B. (2013). Dissecting the anticipation of aversion reveals dissociable neural networks. Cerebral Cortex, 23, 1874-1883.

Gungor, N. Z., \& Paré, D. (2016). Functional heterogeneity in the bed nucleus of the stria terminalis. Journal of Neuroscience, 36, 80388049.

Hallquist, M. N., Hwang, K., \& Luna, B. (2013). The nuisance of nuisance regression: spectral misspecification in a common approach to 
resting-state $\mathrm{fMRI}$ preprocessing reintroduces noise and obscures functional connectivity. Neuroimage, 82, 208-225.

Han, S., Soleiman, M. T., Soden, M. E., Zweifel, L. S., \& Palmiter, R. D. (2015). Elucidating an affective pain circuit that creates a threat memory. Cell, 162, 363-374.

Herrmann, M. J., Boehme, S., Becker, M. P., Tupak, S. V., Guhn, A., Schmidt, B., ... Straube, T. (2016). Phasic and sustained brain responses in the amygdala and the bed nucleus of the stria terminalis during threat anticipation. Human Brain Mapping, 37, 1091-1102.

Holmes, A. J., Hollinshead, M. O., O'keefe, T. M., Petrov, V. I., Fariello, G. R., Wald, L. L., ... Buckner, R. L. (2015). Brain Genomics Superstruct Project initial data release with structural, functional, and behavioral measures. Scientific Data, 2, 150031.

Hrybouski, S., Aghamohammadi-Sereshki, A., Madan, C. R., Shafer, A. T., Baron, C. A., Seres, P., ... Malykhin, N. V. (2016). Amygdala subnuclei response and connectivity during emotional processing. Neuroimage, 133, 98-110.

Iglesias, J. E., Liu, C. Y., Thompson, P., \& Tu, Z. (2011). Robust brain extraction across datasets and comparison with publicly available methods. IEEE Transactions on Medical Imaging, 30, 1617-1634.

Izquierdo, A., Suda, R. K., \& Murray, E. A. (2005). Comparison of the effects of bilateral orbital prefrontal cortex lesions and amygdala lesions on emotional responses in rhesus monkeys. Journal of Neuroscience, 25(37), 8534-8542.

James, A. C., James, G., Cowdrey, F. A., Soler, A., \& Choke, A. (2015). Cognitive behavioural therapy for anxiety disorders in children and adolescents. Cochrane Database Syst Rev, CD004690.

Jo, H. J., Gotts, S. J., Reynolds, R. C., Bandettini, P. A., Martin, A., Cox, R. W., \& Saad, Z. S. (2013). Effective preprocessing procedures virtually eliminate distance-dependent motion artifacts in resting state FMRI. Journal of Applied Mathematics, 2013, 1-9.

Johnston, J. B. (1923). Further contributions to the study of the evolution of the forebrain. The Journal of Comparative Neurology, 35, 337481.

Kaczkurkin, A. N., Moore, T. M., Ruparel, K., Ciric, R., Calkins, M. E., Shinohara, R. T., ... Satterthwaite, T. D. (2016). Elevated amygdala perfusion mediates developmental sex differences in trait anxiety. Biological Psychiatry, 80, 775-785.

Kalin, N. H. (2017). Mechanisms underlying the early risk to develop anxiety and depression: A translational approach. European Neuropsychopharmacology, 27, 543-553.

Kalin, N. H., Fox, A. S., Kovner, R., Riedel, M. K., Fekete, E. M., Roseboom, P. H., ... Oler, J. A. (2016). Overexpressing corticotropinreleasing hormone in the primate amygdala increases anxious temperament and alters its neural circuit. Biological Psychiatry, 80, 345355.

Kalin, N. H., Shelton, S. E., \& Davidson, R. J. (2004). The role of the central nucleus of the amygdala in mediating fear and anxiety in the primate. The Journal of Neuroscience: The Official Journal of the Society for Neuroscience, 24, 5506-5515.

Kalin, N. H., Shelton, S. E., \& Davidson, R. J. (2007). Role of the primate orbitofrontal cortex in mediating anxious temperament. Biological Psychiatry, 62, 1134-1139.

Kalin, N. H., Shelton, S. E., Fox, A. S., Oakes, T. R., \& Davidson, R. J. (2005). Brain regions associated with the expression and contextual regulation of anxiety in primates. Biological Psychiatry, 58, 796-804.

Kamali, A., Sair, H. I., Blitz, A. M., Riascos, R. F., Mirbagheri, S., Keser, Z., \& Hasan, K. M. (2016). Revealing the ventral amygdalofugal pathway of the human limbic system using high spatial resolution diffusion tensor tractography. Brain Structure and Function, 221, 3561-3569.
Kamali, A., Yousem, D. M., Lin, D. D., Sair, H. I., Jasti, S. P., Keser, Z., ... Hasan, K. M. (2015). Mapping the trajectory of the stria terminalis of the human limbic system using high spatial resolution diffusion tensor tractography. Neuroscience Letters, 608, 45-50.

Klein, A., Andersson, J., Ardekani, B. A., Ashburner, J., Avants, B., Chiang M. C., .. Parsey, R. V. (2009). Evaluation of 14 nonlinear deformation algorithms applied to human brain MRI registration. Neuroimage, 46, 786-802

Klumpers, F., Kroes, M. C., Heitland, I., Everaerd, D., Akkermans, S. E., Oosting, R. S., ... Baas, J. M. (2015). Dorsomedial prefrontal cortex mediates the impact of serotonin transporter linked polymorphic region genotype on anticipatory threat reactions. Biological Psychiatry, 78, 582-589.

Knight, D. C., Nguyen, H. T., \& Bandettini, P. A. (2005). The role of the human amygdala in the production of conditioned fear responses. Neurolmage, 26, 1193-1200.

Korn, C. W., Vunder, J., Miró, J., Fuentemilla, L., Hurlemann, R., \& Bach, D. R. (2017). Amygdala lesions reduce anxiety-like behavior in a human benzodiazepine-sensitive approach-avoidance conflict test Biological Psychiatry, 82, 522-531.

Kragel, P. A., Knodt, A. R., Hariri, A. R., \& LaBar, K. S. (2016). Decoding Spontaneous Emotional States in the Human Brain. PLoS Biology, 14 e2000106.

Kragel, P. A., \& LaBar, K. S. (2015). Multivariate neural biomarkers of emotional states are categorically distinct. Social Cognitive and Affective Neuroscience, 10, 1437-1448.

LaBar, K. S., Gatenby, J. C., Gore, J. C., LeDoux, J. E., \& Phelps, E. A (1998). Human amygdala activation during conditioned fear acquisition and extinction: a mixed-trial fMRI study. Neuron, 20, 937-945.

Lange, M. D., Daldrup, T., Remmers, F., Szkudlarek, H. J., Lesting, J., Guggenhuber, S., ... Pape, H. C. (2017). Cannabinoid CB1 receptors in distinct circuits of the extended amygdala determine fear responsiveness to unpredictable threat. Molecular Psychiatry, 22, 1422-1430.

LeDoux, J. E. (2000). Emotion circuits in the brain. Annual Review of Neuroscience, $23,155-184$

LeDoux, J. E. (2007). The amygdala. Current Biology : Cb, 17, R868-R874.

Li, H., Penzo, M. A., Taniguchi, H., Kopec, C. D., Huang, Z. J., \& Li, B. (2013). Experience-dependent modification of a central amygdala fear circuit. Nature Neuroscience, 16, 332-339.

Lindquist, K. A., Satpute, A. B., Wager, T. D., Weber, J., \& Barrett, L. F. (2016). The brain basis of positive and negative affect: Evidence from a meta-analysis of the human neuroimaging literature. Cerebral Cortex, 26, 1910-1922.

Logothetis, N. K. (2008). What we can do and what we cannot do with fMRI. Nature, 453, 869-878.

Mai, J. K., Majtanik, M., \& Paxinos, G. (2015). Atlas of the human brain (4th ed.). San Diego, CA: Academic Press.

Mai, J. K., Paxinos, G., \& Voss, T. (2007). Atlas of the human brain (3rd ed.). San Diego, CA: Academic Press.

Makris, N., Goldstein, J. M., Kennedy, D., Hodge, S. M., Caviness, V. S., Faraone, S. V., ... Seidman, L. J. (2006). Decreased volume of left and total anterior insular lobule in schizophrenia. Schizophrenia Research, 83, 155-171.

Mason, W. A., Capitanio, J. P., Machado, C. J., Mendoza, S. P., \& Amaral, D. G. (2006). Amygdalectomy and responsiveness to novelty in rhesus monkeys (Macaca mulatta): generality and individual consistency of effects. Emotion, 6, 73-81.

McMenamin, B. W., Langeslag, S. J., Sirbu, M., Padmala, S., \& Pessoa, L. (2014). Network organization unfolds over time during periods of anxious anticipation. Journal of Neuroscience, 34, 11261-11273. 
Mechias, M. L., Etkin, A., \& Kalisch, R. (2010). A meta-analysis of instructed fear studies: implications for conscious appraisal of threat. Neurolmage, 49, 1760-1768.

Meyer, C. H., Padmala, S., \& Pessoa, L. (2017). Tracking dynamic threat imminence. bioRxiv.

Mobbs, D., Marchant, J. L., Hassabis, D., Seymour, B., Tan, G., Gray, M., ... Frith, C. D. (2009). From threat to fear: the neural organization of defensive fear systems in humans. The Journal of Neuroscience: The Official Journal of the Society for Neuroscience, 29, 12236-12243.

Mobbs, D., Petrovic, P., Marchant, J. L., Hassabis, D., Weiskopf, N., Seymour, B., ... Frith, C. D. (2007). When fear is near: threat imminence elicits prefrontal-periaqueductal gray shifts in humans. Science, 317, 1079-1083.

Mobbs, D., Yu, R., Rowe, J. B., Eich, H., FeldmanHall, O., \& Dalgleish, T. (2010). Neural activity associated with monitoring the oscillating threat value of a tarantula. Proceedings of the National Acadademy of Sciences Usa, 107, 20582-20586.

Motta, S. C., Carobrez, A. P., \& Canteras, N. S. (2017). The periaqueductal gray and primal emotional processing critical to influence complex defensive responses, fear learning and reward seeking. Neuroscience and Biobehavioral Reviews, 76, 39-47.

Motzkin, J. C., Philippi, C. L., Oler, J. A., Kalin, N. H., Baskaya, M. K., \& Koenigs, M. (2015). Ventromedial prefrontal cortex damage alters resting blood flow to the bed nucleus of stria terminalis. Cortex, 64, 281-288.

Münsterkötter, A. L., Notzon, S., Redlich, R., Grotegerd, D., Dohm, K., Arolt, V., ... Dannlowski, U. (2015). Spider or no spider? Neural correlates of sustained and phasic fear in spider phobia. Depression and Anxiety, 32, 656-663.

Nacewicz, B. M., Alexander, A. L., Kalin, N. H., \& Davidson, R. J. (2014). The neurochemical underpinnings of human amygdala volume including subregional contributions. Biological Psychiatry, 75, S222.

Najafi, M., Kinnison, J., \& Pessoa, L. (2017). Intersubject brain network organization during dynamic anxious anticipation. Frontiers in Human Neuroscience, 11,

Nashold, B. S., Wilson, W. P., \& Slaughter, D. G. (1969). Sensations evoked by stimulation in the midbrain of man. Journal of Neurosurgery, 30, 14-24.

Nauta, W. J. (1961). Fibre degeneration following lesions of the amygdaloid complex in the monkey. Journal of Anatomy, 95, 515-531.

Nichols, T., Brett, M., Andersson, J., Wager, T., \& Poline, J. B. (2005). Valid conjunction inference with the minimum statistic. Neuroimage, 25(3), 653-660.

Nooner, K. B., Colcombe, S. J., Tobe, R. H., Mennes, M., Benedict, M. M., Moreno, A. L., ... Milham, M. P. (2012). The NKI-Rockland sample: A model for accelerating the pace of discovery science in psychiatry. Frontiers in Neuroscience, 6, 152.

Nummenmaa, L., \& Saarimaki, H. (2017). Emotions as discrete patterns of systemic activity. Neuroscience Letters.

Oler, J. A., Birn, R. M., Patriat, R., Fox, A. S., Shelton, S. E., Burghy, C. A., ... Kalin, N. H. (2012). Evidence for coordinated functional activity within the extended amygdala of non-human and human primates. Neuroimage, 61, 1059-1066.

Oler, J. A., Fox, A. S., Shackman, A. J., \& Kalin, N. H. (2016). The central nucleus of the amygdala is a critical substrate for individual differences in anxiety. In D. G. Amaral \& R. Adolphs (Eds.), Living without an amygdala. NY: Guilford.

Oler, J. A., Fox, A. S., Shelton, S. E., Rogers, J., Dyer, T. D., Davidson, R. J., ... Kalin, N. H. (2010). Amygdalar and hippocampal substrates of anxious temperament differ in their heritability. Nature, 466, 864868.
Oler, J. A., Tromp, D. P., Fox, A. S., Kovner, R., Davidson, R. J., Alexander, A. L., ... Fudge, J. L. (2017). Connectivity between the central nucleus of the amygdala and the bed nucleus of the stria terminalis in the non-human primate: neuronal tract tracing and developmental neuroimaging studies. Brain Structure and Function, 222, 21-39.

Ongur, D., \& Price, J. L. (2000). The organization of networks within the orbital and medial prefrontal cortex of rats, monkeys and humans. Cerebral Cortex, 10, 206-219.

Ongur, D., Ferry, A. T., \& Price, J. L. (2003). Architectonic subdivision of the human orbital and medial prefrontal cortex. Journal of Comparative Neurology, 460, 425-449.

Pare, D., \& Duvarci, S. (2012). Amygdala microcircuits mediating fear expression and extinction. Current Opinion in Neurobiology, 22, 717723.

Pedersen, W. S., Balderston, N. L., Miskovich, T. A., Belleau, E. L., Helmstetter, F. J., \& Larson, C. L. (2017). The effects of stimulus novelty and negativity on BOLD activity in the amygdala, hippocampus, and bed nucleus of the stria terminalis. Soc Cogn Affect Neurosci, 12, 748-757.

Penzo, M. A., Robert, V., \& Li, B. (2014). Fear conditioning potentiates synaptic transmission onto long-range projection neurons in the lateral subdivision of central amygdala. Journal of Neuroscience, 34, 2432-2437.

Penzo, M. A., Robert, V., Tucciarone, J., De Bundel, D., Wang, M., Van Aelst, L., ... Li, B. (2015). The paraventricular thalamus controls a central amygdala fear circuit. Nature, 519, 455-459.

Pessoa, L. (2017). A network model of the emotional brain. Trends in Cognitive Sciences, 21, 357-371.

Poldrack, R. A., Baker, C. I., Durnez, J., Gorgolewski, K. J., Matthews, P. M., Munafo, M. R., ... Yarkoni, T. (2017). Scanning the horizon: towards transparent and reproducible neuroimaging research. Nature Reviews Neuroscience, 18, 115-126.

Power, J. D., Schlaggar, B. L., \& Petersen, S. E. (2015). Recent progress and outstanding issues in motion correction in resting state fMRI. Neurolmage, 105, 536-551.

Richardson, D. E., \& Akil, H. (1977). Pain reduction by electrical brain stimulation inman. Part 1: Acute administration in periaqueductal and periventricular sites. Journal of Neurosurgery, 47, 178-183.

Roesch, M. R., Esber, G. R., Li, J., Daw, N. D., \& Schoenbaum, G. (2012). Surprise! Neural correlates of Pearce-Hall and Rescorla-Wagner coexist within the brain. European Journal of Neuroscience, 35, 11901200.

Rudebeck, P. H., Saunders, R. C., Prescott, A. T., Chau, L. S., \& Murray, E. A. (2013). Prefrontal mechanisms of behavioral flexibility, emotion regulation and value updating. Nature Neuroscience, 16, 1140-1145.

Sabatinelli, D., Fortune, E. E., Li, Q., Siddiqui, A., Krafft, C., Oliver, W. T., ... Jeffries, J. (2011). Emotional perception: Meta-analyses of face and natural scene processing. Neurolmage, 54, 2524-2533.

Salomon, J. A., Haagsma, J. A., Davis, A., de Noordhout, C. M., Polinder, S., Havelaar, A. H., ... Vos, T. (2015). Disability weights for the Global Burden of Disease 2013 study. The Lancet. Global Health, 3, e712-e723.

Sato, M., Ito, M., Nagase, M., Sugimura, Y. K., Takahashi, Y., Watabe, A. M., $\&$ Kato, F. (2015). The lateral parabrachial nucleus is actively involved in the acquisition of fear memory in mice. Molecular Brain, 8, 22.

Satpute, A. B., Wager, T. D., Cohen-Adad, J., Bianciardi, M., Choi, J. K., Buhle, J. T., ... Barrett, L. F. (2013). Identification of discrete functional subregions of the human periaqueductal gray. Proceedings of the National Academy of Sciences of the United States of America, 110, 17101-17106. 
Sergerie, K., Chochol, C., \& Armony, J. L. (2008). The role of the amygdala in emotional processing: a quantitative meta-analysis of functional neuroimaging studies. Neuroscience and Biobehavioral Reviews, 32, 811-830.

Shackman, A. J., \& Fox, A. S. (2016). Contributions of the central extended amygdala to fear and anxiety. The Journal of Neuroscience : The Official Journal of the Society for Neuroscience, 36, 8050-8063.

Shackman, A. J., \& Fox, A. S. (2018). How are emotions organized in the brain?. In A. S. Fox, R. C. Lapate, A. J. Shackman, \& R. J. Davidson (Eds.), The nature of emotion. Fundamental questions (2nd ed.). New York, NY: Oxford University Press.

Shackman, A. J., Fox, A. S., Oler, J. A., Shelton, S. E., Davidson, R. J., \& Kalin, N. H. (2013). Neural mechanisms underlying heterogeneity in the presentation of anxious temperament. Proceedings of the National Academy of Sciences of the United States of America, 110, 61456150.

Shackman, A. J., Fox, A. S., Oler, J. A., Shelton, S. E., Oakes, T. R., Davidson, R. J., \& Kalin, N. H. (2017). Heightened extended amygdala metabolism following threat characterizes the early phenotypic risk to develop anxiety-related psychopathology. Molecular Psychiatry, 22, 724-732.

Shackman, A. J., Fox, A. S., \& Seminowicz, D. A. (2015). The cognitiveemotional brain: Opportunities and challenges for understanding neuropsychiatric disorders. Behavioral and Brain Sciences, 38, e86.

Shackman, A. J., Kaplan, C. M., Stockbridge, M. D., Tillman, R. M., Tromp, D. P. M., Fox, A. S., \& Gamer, M. (2016). The neurobiology of anxiety and attentional biases to threat: Implications for understanding anxiety disorders in adults and youth. Journal of Experimental Psychopathology, 7, 311-342.

Shackman, A. J., McMenamin, B. W., Maxwell, J. S., Greischar, L. L., \& Davidson, R. J. (2009). Right dorsolateral prefrontal cortical activity and behavioral inhibition. Psychological Science, 20, 1500-1506.

Shackman, A. J., Salomons, T. V., Slagter, H. A., Fox, A. S., Winter, J. J., \& Davidson, R. J. (2011). The integration of negative affect, pain and cognitive control in the cingulate cortex. Nature Reviews Neuroscience, 12, 154-167.

Shackman, A. J., Tromp, D. P. M., Stockbridge, M. D., Kaplan, C. M., Tillman, R. M., \& Fox, A. S. (2016). Dispositional negativity: An integrative psychological and neurobiological perspective. Psychological Bulletin, 142, 1275-1314.

Shattuck, D. W., Sandor-Leahy, S. R., Schaper, K. A., Rottenberg, D. A., \& Leahy, R. M. (2001). Magnetic resonance image tissue classification using a partial volume model. Neuroimage, 13, 856-876.

Šidák, Z. K. (1967). Rectangular confidence regions for the means of multivariate normal distributions. Journal of the American Statistical Association, 62, 626-633.

Siegel, J. S., Power, J. D., Dubis, J. W., Vogel, A. C., Church, J. A., Schlaggar, B. L., \& Petersen, S. E. (2014). Statistical improvements in functional magnetic resonance imaging analyses produced by censoring high-motion data points. Human Brain Mapping, 35, 1981-1996.

Sladky, R., Geissberger, N., Pfabigan, D. M., Kraus, C., Tik, M., Woletz, M., ... Windischberger, C. (2017). Unsmoothed functional MRI of the human amygdala and bed nucleus of the stria terminalis during processing of emotional faces. Neuroimage,

Smith, S. M. (2002). Fast robust automated brain extraction. Human Brain Mapping, 17, 143-155.

Somerville, L. H., Wagner, D. D., Wig, G. S., Moran, J. M., Whalen, P. J., \& Kelley, W. M. (2013). Interactions between transient and sustained neural signals support the generation and regulation of anxious emotion. Cerebral Cortex, 23, 49-60.
Somerville, L. H., Whalen, P. J., \& Kelley, W. M. (2010). Human bed nucleus of the stria terminalis indexes hypervigilant threat monitoring. Biological Psychiatry, 68, 416-424.

Stelzer, J., Lohmann, G., Mueller, K., Buschmann, T., \& Turner, R. (2014). Deficient approaches to human neuroimaging. Frontiers in Human Neuroscience, 8, 462.

Stevens, J. S., Kim, Y. J., Galatzer-Levy, I. R., Reddy, R., Ely, T. D., Nemeroff, C. B., ... Ressler, K. J. (2017). Amygdala reactivity and anterior cingulate habituation predict posttraumatic stress disorder symptom maintenance after acute civilian trauma. Biological Psychiatry, 81, 1023-1029.

Stocker, T. (2007). On the asymptotic bias of OLS in dynamic regression models with autocorrelated errors. Statistical Papers, 48, 81-93.

Stout, D. M., Shackman, A. J., Pedersen, W. S., Miskovich, T. A., \& Larson, C. L. (2017). Neural circuitry governing anxious individuals' misallocation of working memory to threat. Scientific Reports, 7, 8742.

Theiss, J. D., Ridgewell, C., McHugo, M., Heckers, S., \& Blackford, J. U. (2017). Manual segmentation of the human bed nucleus of the stria terminalis using 3T MRI. Neurolmage, 146, 288-292.

Torrisi, S., O'connell, K., Davis, A., Reynolds, R., Balderston, N., Fudge, J. L., ... Ernst, M. (2015). Resting state connectivity of the bed nucleus of the stria terminalis at ultra-high field. Human Brain Mapping, 36, 4076-4088.

Tovote, P., Esposito, M. S., Botta, P., Chaudun, F., Fadok, J. P., Markovic, M., ... Luthi, A. (2016). Midbrain circuits for defensive behaviour. Nature, 534, 206-212.

Tovote, P., Fadok, J. P., \& Luthi, A. (2015). Neuronal circuits for fear and anxiety. Nature Reviews. Neuroscience, 16, 317-331.

Turner, R., \& Geyer, S. (2014). Comparing like with like: the power of knowing where you are. Brain Connectivity, 4, 547-557.

Tustison, N. J., Cook, P. A., Klein, A., Song, G., Das, S. R., Duda, J. T., ... Avants, B. B. (2014). Large-scale evaluation of ANTs and FreeSurfer cortical thickness measurements. Neuroimage, 99, 166-179.

Tyszka, J. M., \& Pauli, W. M. (2016). In vivo delineation of subdivisions of the human amygdaloid complex in a high-resolution group template. Human Brain Mapping, 37, 3979-3998.

Uddin, L. Q., Kinnison, J., Pessoa, L., \& Anderson, M. L. (2014). Beyond the tripartite cognition-emotion-interoception model of the human insular cortex. Journal of Cognitive Neuroscience, 26, 16-27.

van Well, S., Visser, R. M., Scholte, H. S., \& Kindt, M. (2012). Neural substrates of individual differences in human fear learning: evidence from concurrent fMRI, fear-potentiated startle, and US-expectancy data. Cognitive, Affective, \& Behavioral Neuroscience, 12, 499-512.

Wager, T. D., Kang, J., Johnson, T. D., Nichols, T. E., Satpute, A. B., \& Barrett, L. F. (2015). A Bayesian model of category-specific emotional brain responses. PLoS Computational Biology, 11, e1004066.

Wiegert, J. S., Mahn, M., Prigge, M., Printz, Y., \& Yizhar, O. (2017). Silencing neurons: Tools, applications, and experimental constraints. Neuron, 95, 504-529.

Williams, L. E., Oler, J. A., Fox, A. S., McFarlin, D. R., Rogers, G. M., Jesson, M. A., ... Kalin, N. H. (2015). Fear of the unknown: Uncertain anticipation reveals amygdala alterations in childhood anxiety disorders. Neuropsychopharmacology, 40, 1428-1435.

Wise, R. A., \& Koob, G. F. (2014). The development and maintenance of drug addiction. Neuropsychopharmacology : Official Publication of the American College of Neuropsychopharmacology, 39, 254-262.

Wood, K. H., Ver Hoef, L. W., \& Knight, D. C. (2014). The amygdala mediates the emotional modulation of threat-elicited skin conductance response. Emotion (Washington, D.C.), 14, 693-700.

Yilmazer-Hanke, D. M. (2012). Amygdala. In J. K. Mai \& G. Paxinos (Eds.), The human nervous system (pp. 759-834. San Diego: Academic Press. 
Yu, K., Ahrens, S., Zhang, X., Schiff, H., Ramakrishnan, C., Fenno, L., ... $\mathrm{Li}$, B. (2017). The central amygdala controls learning in the lateral amygdala. Nature Neuroscience, 20, 1680-1685.

\section{SUPPORTING INFORMATION}

Additional Supporting Information may be found online in the supporting information tab for this article.
How to cite this article: Tillman RM, Stockbridge MD, Nacewicz $\mathrm{BM}$, et al. Intrinsic functional connectivity of the central extended amygdala. Hum Brain Mapp. 2018;39:1291-1312. https://doi.org/10.1002/hbm.23917 